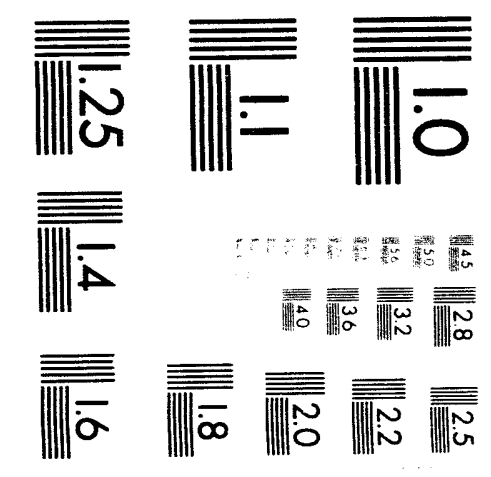



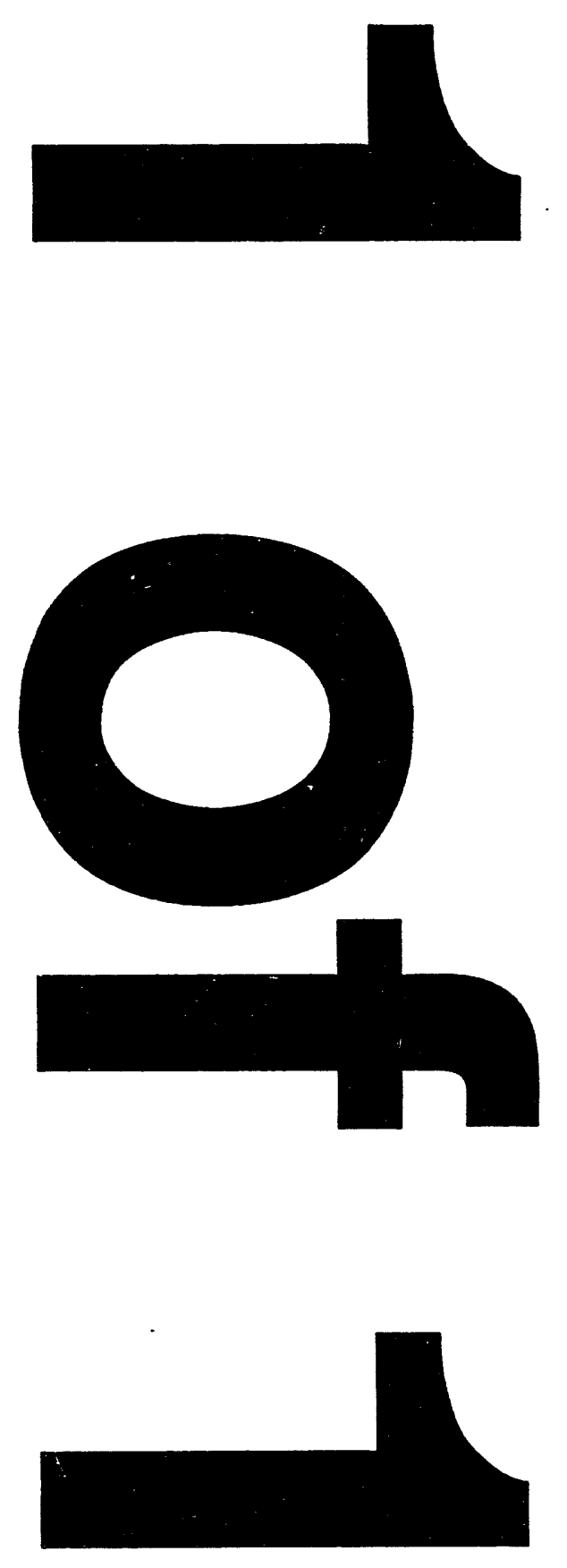
PNL-8892

UC-510

\title{
1/12-Scale Mixing Interface Visualization and Buoyant Particle Release Tests in Support of Tank 241-SY-101 Hydrogen Mitigation
}

\author{
E. J. Eschbach \\ C. W. Enderlin
}

October 1993

Prepared for

the U.S. Department of Energy

under Contract DE-AC06-76RLO 1830

Pacific Northwest Laboratory

Richland, Washington 99352 


\section{Summary}

In support of tank waste safety programs, visualization tests were performed in the $1 / 12$-scale tank facility, using a low-viscosity simulant. The primary objective of the tests was to obtain video records of the transient jet-sludge interaction. The intent is that these videos will provide useful qualitative data for comparison with model predictions.

Two tests were initially planned: mixing interface visualization (MIV) and buoyant particle release (BPR). Completion of the buoyant particle release test was set aside in order to complete additional MIV tests.

Rheological measurements were made on simulant samples before testing, and the simulant was found to exhibit thixotropic behavior. Shear vane measurements were also made on an in-situ analog of the 1/12-scale tank simulant. Simulant shear strength has been observed to be time dependent.

The primary objective of obtaining video records of jet-sludge interaction was satisfied, and the records yielded jet location information which may be of use in completing model comparisons. The modeling effort is not part of this task, but this report also discusses test specific instrumentation, visualization techniques, and shear vane instrumentation which would enable improved characterization of jet-sludge interaction and simulant characteristics. 


\section{Acknowledgements}

The work described in this report was conducted for the Tank 241-SY-101 Hydrogen Mitigation Project. The project manager is J. W. Lentsch (Westinghouse Hanford Company). Direction and project management support was provided by M. R. Kreiter, J. B. Colson, of Pacific Northwest Laboratory. Modeling task needs and technical test direction resulted from discussions with $\mathbf{R}$. T. Alleman, J. M. Bates, L. L. Eyler, T. E. Michener, and D. S. Trent, of Pacific Northwest Laboratory.

The authors wish to thank K. D. Hinkle and P. J. Titzler, Pacific Northwest Laboratory; B. L. Cox and R. G. Magnuson, Boeing Information Services, for their dedicated assistance in completing the tests. D. A. Schulz, J. W. Nageley, and F. M. Ryan, Pacific Northwest Laboratory contributed to the completion of this report. 


\section{Contents}

Summary $\ldots \ldots \ldots \ldots \ldots \ldots \ldots \ldots \ldots \ldots \ldots \ldots \ldots \ldots \ldots \ldots$ ii

Acknowledgements $\ldots \ldots \ldots \ldots \ldots \ldots \ldots \ldots \ldots \ldots \ldots$

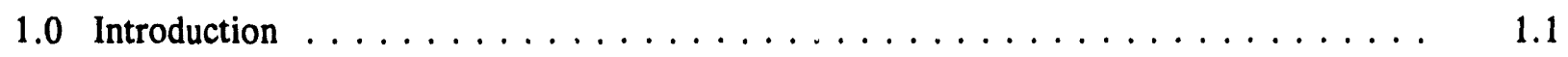

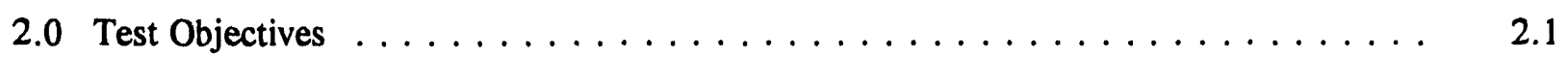

2.1 Mixing Interface Visualization (MIV) $\ldots \ldots \ldots \ldots \ldots \ldots \ldots \ldots \ldots$

2.2 Buoyant Particle Release (BPR) $\ldots \ldots \ldots \ldots \ldots \ldots \ldots \ldots \ldots \ldots$

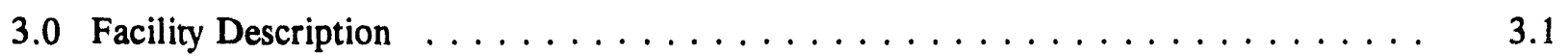

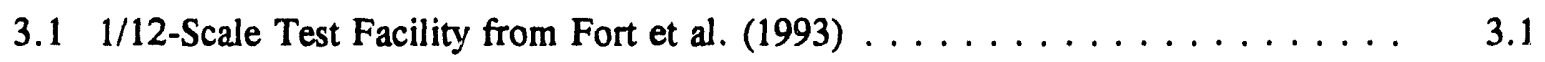

3.2 Shear Vane $\operatorname{Tank} \ldots \ldots \ldots \ldots \ldots \ldots \ldots \ldots \ldots \ldots \ldots$

4.0 Instrumentation and Visualization Strategy $\ldots \ldots \ldots \ldots \ldots \ldots \ldots \ldots$

4.1 Process Measurement $\ldots \ldots \ldots \ldots \ldots \ldots \ldots \ldots \ldots \ldots \ldots \ldots \ldots$

4.2 Jet Velocity $\&$ Jet Progress $\ldots \ldots \ldots \ldots \ldots \ldots \ldots \ldots \ldots \ldots$

4.2.1 Single Point Jet Velocity - Dual Jet Configuration Only . . . . . . . . . . 4.2

4.2 .2 Visualization Strategy $\ldots \ldots \ldots \ldots \ldots \ldots \ldots \ldots \ldots . \ldots \ldots$

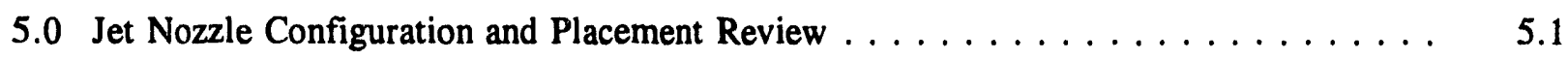

5.1 Jet Analysis Background $\ldots \ldots \ldots \ldots \ldots \ldots \ldots \ldots \ldots \ldots \ldots \ldots$

5.2 Estimate of Jet Penetration Length $\ldots \ldots \ldots \ldots \ldots \ldots \ldots \ldots$

5.3 Estimate of Time of Flight for Jet Penetration $\ldots \ldots \ldots \ldots \ldots$

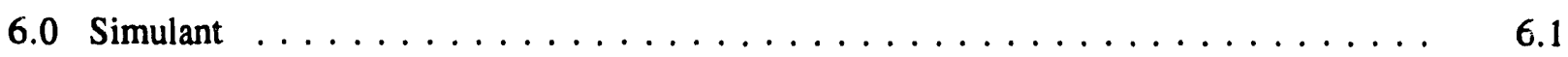

6.1 Rheological Measurements $\ldots \ldots \ldots \ldots \ldots \ldots \ldots \ldots \ldots \ldots \ldots \ldots$

7.0 Buoyant Sludge Development $\ldots \ldots \ldots \ldots \ldots \ldots \ldots \ldots \ldots \ldots \ldots$

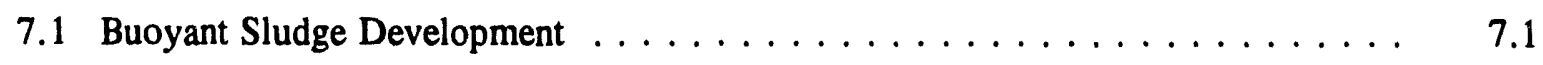

vii 
7.2 Suggested Buoyant Sludge Procedure $\ldots \ldots \ldots \ldots \ldots \ldots \ldots \ldots . \ldots \ldots$

8.0 Test Descriptions and Results $\ldots \ldots \ldots \ldots \ldots \ldots \ldots \ldots \ldots$

8.1 General Test Outline $\ldots \ldots \ldots \ldots \ldots \ldots \ldots \ldots \ldots \ldots \ldots$

8.2 Mixing Interface Visualization (MIV) Test $\# 1 \ldots \ldots \ldots \ldots \ldots \ldots$

8.2.1 Measurement Results for MIV $\# 1 \ldots \ldots \ldots \ldots \ldots \ldots$

8.3 Mixing Interface Visualization (MIV) Test $\# 2 \ldots \ldots \ldots \ldots$

8.3.1 Measurement Results for MIV $\# 2 \ldots \ldots \ldots \ldots \ldots$

8.4 Mixing Interface Visualization (MIV) Test $\# 3 \ldots \ldots \ldots \ldots \ldots \ldots$

8.5 Mixing Interface Visualization (MIV) Test $\# 4 \ldots \ldots \ldots \ldots \ldots \ldots$

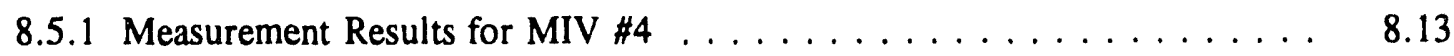

8.6 Shear Strength Measurements for Mixing Interface Visualization Tests _. . . . 8.14

8.6.1 Shear Strength Equipment $\ldots \ldots \ldots \ldots \ldots \ldots \ldots \ldots$

8.6.2 Shear Vane Procedure $\ldots \ldots \ldots \ldots \ldots \ldots \ldots \ldots$

8.6.3 Shear Vane Test Data $\ldots \ldots \ldots \ldots \ldots \ldots \ldots \ldots . \ldots \ldots$

8.6 .4 Shear Strength Results $\ldots \ldots \ldots \ldots \ldots \ldots \ldots \ldots$

8.7 Shear Vane Conclusions $\ldots \ldots \ldots \ldots \ldots \ldots \ldots \ldots \ldots \ldots \ldots \ldots$

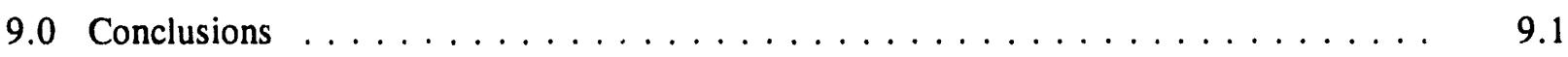

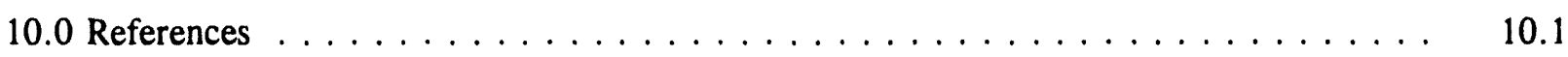




\section{Figures}

3.1 1/12-Scale Tank with Mixing Pump Model $\ldots \ldots \ldots \ldots \ldots \ldots \ldots \ldots$

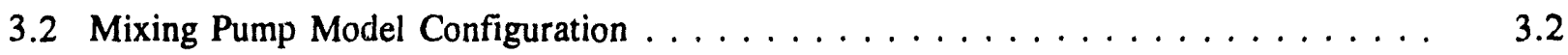

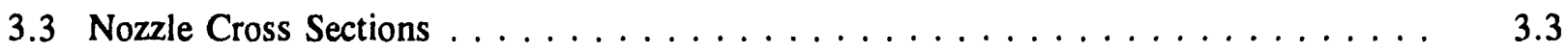

$3.41 / 12-$ Scale Facility and Auxiliary Tanks $\ldots \ldots \ldots \ldots \ldots \ldots \ldots$

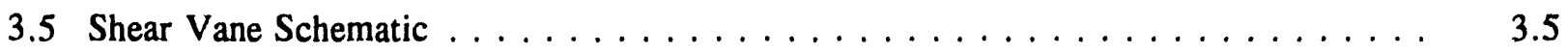

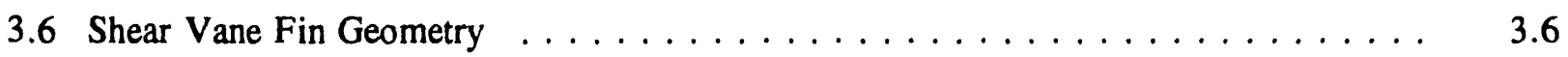

4.1 Camera View Schematic $\ldots \ldots \ldots \ldots \ldots \ldots \ldots \ldots \ldots \ldots$

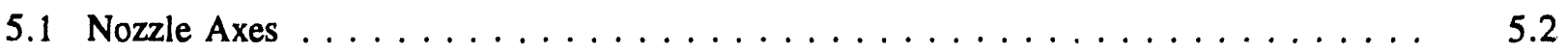

6.1 Simulant Relative Viscosity and Normalized Solids Concentration . . . . . . . . . 6.2

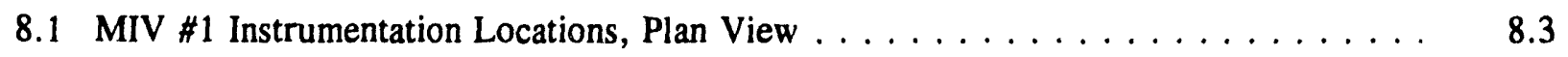

8.2 MIV \#1 Temperature $\ldots \ldots \ldots \ldots \ldots \ldots \ldots \ldots \ldots \ldots$

8.3 MIV \#1 Process Flow $\ldots \ldots \ldots \ldots \ldots \ldots \ldots \ldots \ldots \ldots$

8.4 MIV \#1 Buried EMF Probe Response $\ldots \ldots \ldots \ldots \ldots \ldots$

8.5 Post MIV \#1 Burrowing Pattern $\ldots \ldots \ldots \ldots \ldots \ldots \ldots \ldots \ldots$

8.6 MIV \#2 Temperature $\ldots \ldots \ldots \ldots \ldots \ldots \ldots \ldots \ldots \ldots$

8.7 MIV \#2 Process Flow $\ldots \ldots \ldots \ldots \ldots \ldots \ldots \ldots \ldots \ldots \ldots$

8.8 MIV \#3 Process Flow $\ldots \ldots \ldots \ldots \ldots \ldots \ldots \ldots \ldots \ldots \ldots \ldots \ldots \ldots \ldots$

8.9 MIV \#3 Temperature $\ldots \ldots \ldots \ldots \ldots \ldots \ldots \ldots \ldots \ldots \ldots \ldots \ldots \ldots \ldots$

8.10 MIV \#4 Temperature $\ldots \ldots \ldots \ldots \ldots \ldots \ldots \ldots \ldots \ldots \ldots \ldots$

8.11 MIV \#4 Process Flow $\ldots \ldots \ldots \ldots \ldots \ldots \ldots \ldots \ldots \ldots$

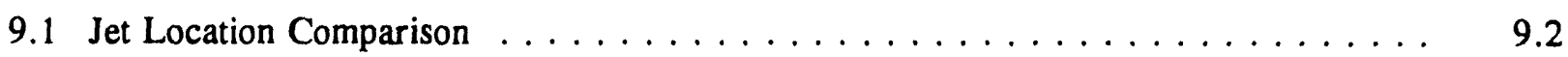

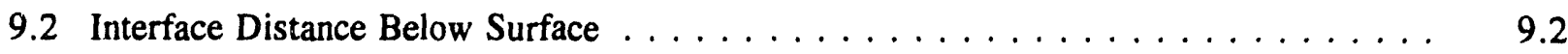




\section{Tables}

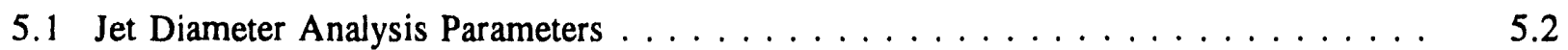

5.2 Exit Nozzle Penetration Length $\ldots \ldots \ldots \ldots \ldots \ldots \ldots \ldots$

6.1 Low-viscosity Simulant Nominal Composition $\ldots \ldots \ldots \ldots . \ldots \ldots$

6.2 Simulant Relative Viscosity and Normalized Solids Concentration Values . . . . . . 6.3

7.1 Number of Spheres to Create $20 \%$ Void Fraction $\left(29,452 \mathrm{in}^{3}\right.$ of sludge $) \ldots \ldots . \ldots 7.2$

8.1 Chronology of $1 / 12$-Scale Testing $\ldots \ldots \ldots \ldots \ldots \ldots \ldots \ldots \ldots$

8.2 Nominal Location of Instrumentation Probes for MIV $\# 1 \ldots \ldots \ldots$

8.3 Conditions for MIV $\# 1 \ldots \ldots \ldots \ldots \ldots \ldots \ldots \ldots \ldots$

8.4 MIV \#1 Jet - Progression Table $\ldots \ldots \ldots \ldots \ldots \ldots \ldots \ldots \ldots$

8.5 Interface Location for MIV $\# 1 \ldots \ldots \ldots \ldots$

8.6 Conditions for MIV $\# 2 \ldots \ldots \ldots \ldots \ldots \ldots$

8.7 MIV \#2 Jet - Progression Table $\ldots \ldots \ldots \ldots \ldots \ldots \ldots \ldots \ldots$

8.8 Interface Location for MIV $\# 2 \ldots \ldots \ldots \ldots \ldots \ldots \ldots \ldots$

8.9 Conditions for MIV $\# 3 \ldots \ldots \ldots \ldots \ldots \ldots \ldots \ldots \ldots \ldots$

8.10 Conditions for $\mathrm{MIV} \# 4 \ldots \ldots \ldots \ldots \ldots \ldots \ldots \ldots$

8.11 MIV \#4 Jet - Progression Table $\ldots \ldots \ldots \ldots \ldots \ldots \ldots \ldots \ldots \ldots$

8.12 Interface Location for MIV $\# 4 \ldots \ldots \ldots \ldots \ldots \ldots \ldots$

8.13 Viscosity Estimates for Sludge Layer $\ldots \ldots \ldots \ldots \ldots \ldots \ldots$

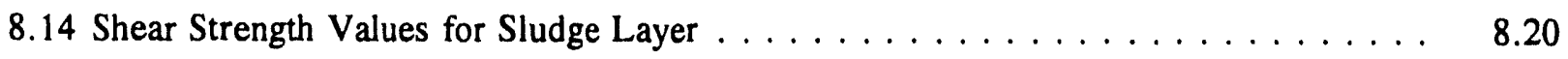

8.15 Viscosity Estimates for Sludge Layer $\ldots \ldots \ldots \ldots \ldots \ldots \ldots \ldots \ldots$ 


\subsection{Introduction}

Based on the analysis of data from tank 241-SY-101 and on physical modeling, it has been concluded that gas accumulation in the sludge layer of the tank is a key mechanism of the gas burp phenomena. The actual gas generation rate is evidently low. Therefore, if gas accumulation could be eliminated by allowing the gas to escape continuously at the same rate as generated, the build-up of a combustible mixture could be avoided. Mixer-pump action has been identified as a potential method of eliminating gas accumulation.

Computational models have been developed to assist in the evaluation of mixer-pump operational issues. It is useful to compare the predictions of these models with experimental observations. This document describes two types of 1/12-scale tests that focused on providing such experimental observations. The tests are based in part on the experiments described in (Fort et al., 1993), and utilized the same test facility and low-viscosity simulant described therein. Rheological measurements were made on small quantities of the simulant before 1/12-scale testing was performed. Shear-strength measurements were obtained on the day of the test from a shear vane placed in a separate tank.

Objectives of the scaled tests were to obtain a video record of 1) the location of the jet breaking through the settled simulant sludge layer, and 2) the jet action as it penetrates a buoyant sludge. Hereafter, these tests are referred to as the mixing interface visualization (MIV) test and the buoyant particle release (BPR) test, respectively. To complete both tests using only one batch of simulant, the MIV test was scheduled first, before the BPR test. A limited number of measurements were made during the tests. Reiterating, the tests are transient and the primary results of testing are video records (qualitative information).

After the first MIV test, the results were reviewed by cognizant modeling and experimental staff. This preliminary assessment raised questions regarding jet progression within the sludge and how the flow splits between the two nozzles. Because these questions could not be resolved at the time, the modeling and experimental staff agreed that repeating the MIV test was preferable to completing the BPR test. Therefore, additional MIV tests were conducted and the 1/12-scale BPR test was not conducted. Activities related to preparation for the BPR test are, however, included in this report. Buoyant particle characteristics such as retention and stability were evaluated qualitatively in bench scale tests, and a strategy to incorporate the selected particles into a larger scale tank was proposed.

This introductory section outlines the background and purpose of these experiments, and the approach to testing. Section 2 details the test objectives. Section 3 describes the test facility, and Section 4 describes the associated test instrumentation. Section 5 reviews the experimental considerations regarding jet nozzle configuration and placement, and the estimating procedures for jet penetration length and time of flight. Section 6 covers the simulant formula and rheological properties. Section 7 covers the BPR preparatory work, and presents some preliminary conclusions. Section 8 presents the test procedures and describes and discusses the observations and measurements made during MIV and shear strength tests. Section 9 details the major conclusions of this experimental program, and Section 10 is a reference list. 


\subsection{Test Objectives}

The objectives of the two tests were re-creation of the test conditions that gave rise to the observed mixing interface behavior described in (Fort et. al. 1993) and to obtain a video record of the location of the jet breaking through the settled simulant sludge layer. Secondary objectives such as quantitative measurements were accommodated to the extent possible. Given the project constraints, shakedown tests to perfect video recording, instrumentation placement, or shear strength measurements were not possible.

\subsection{Mixing Interface Visualization (MIV)}

During the course of 1/12-scale low-viscosity simulant testing for SY-101 jet mixing described in (Fort et al. 1993), distinct visual observations were made of the vertical growth of the interface between the settled sludge layer and the transparent supernatant layer. The dynamics of the interface were noteworthy and attempts to make video records of the local and global effects of the mixing jet were planned for eventual comparison with the TEMPEST (Trent and Eyler, 1991) code predictions of tank behavior. The optical clarity of the supernatant liquid degraded over time which precluded the completion of a video record. Therefore, the objective of the MIV task was to create similar test conditions that resulted in the observed interface dynamics in a newly prepared batch of simulant, such that a video record of the behavior could be completed.

\subsection{Buoyant Particle Release (BPR)}

It has been deduced that the sludge layer in tank SY-101 becomes buoyant over time due to trapped gas. The interaction of a buoyant sludge with a mixing jet is also of interest from both phenomenological and model comparison perspectives. Sludge layer mixing and suspension tests have been performed with a non-buoyant sludge layer created by the settling of simulant particulate and are described in (Fort et al. 1993). The primary objectives of the BPR test were to develop a repeatable, controllable method by which the simulant sludge could be made buoyant, i.e. a representation of trapped gas, and obtain a video record of the interaction between the mixing jet and the buoyant sludge.

In order to create a buoyant sludge, efforts were focused on identification of buoyant particles that could be inserted and retained in the settled particulates (sludge) layer of the waste simulant. Injection of a gas into the simulant sludge could be argued to be a more realistic representation of the conditions in tank 241-SY-101. However, the physics of rising compressible bubbles are not currently included in the predictive model; therefore, inducing buoyancy by injection of a gas was not a requirement for model comparisons. 


\subsection{Facility Description}

The 1/12-scale facility and instrumentation used in the tests are described in the following section.

\subsection{1/12-Scale Test Facility from Fort et al. (1993)}

The experiments were performed in a 1/12-scale model of a double shell tank located in the 336 Building at the Hanford Site. The tank can be configured to represent component arrangements in actual waste tanks by using models of internal components such as air-lift circulators, steam coils, radiation dry wells, and other tank hardware. The present configuration neglects all internals except for the mixer pump assembly. The tank, made of 304L stainless steel, is shown in Figure 3.1 with the mixing pump installed.

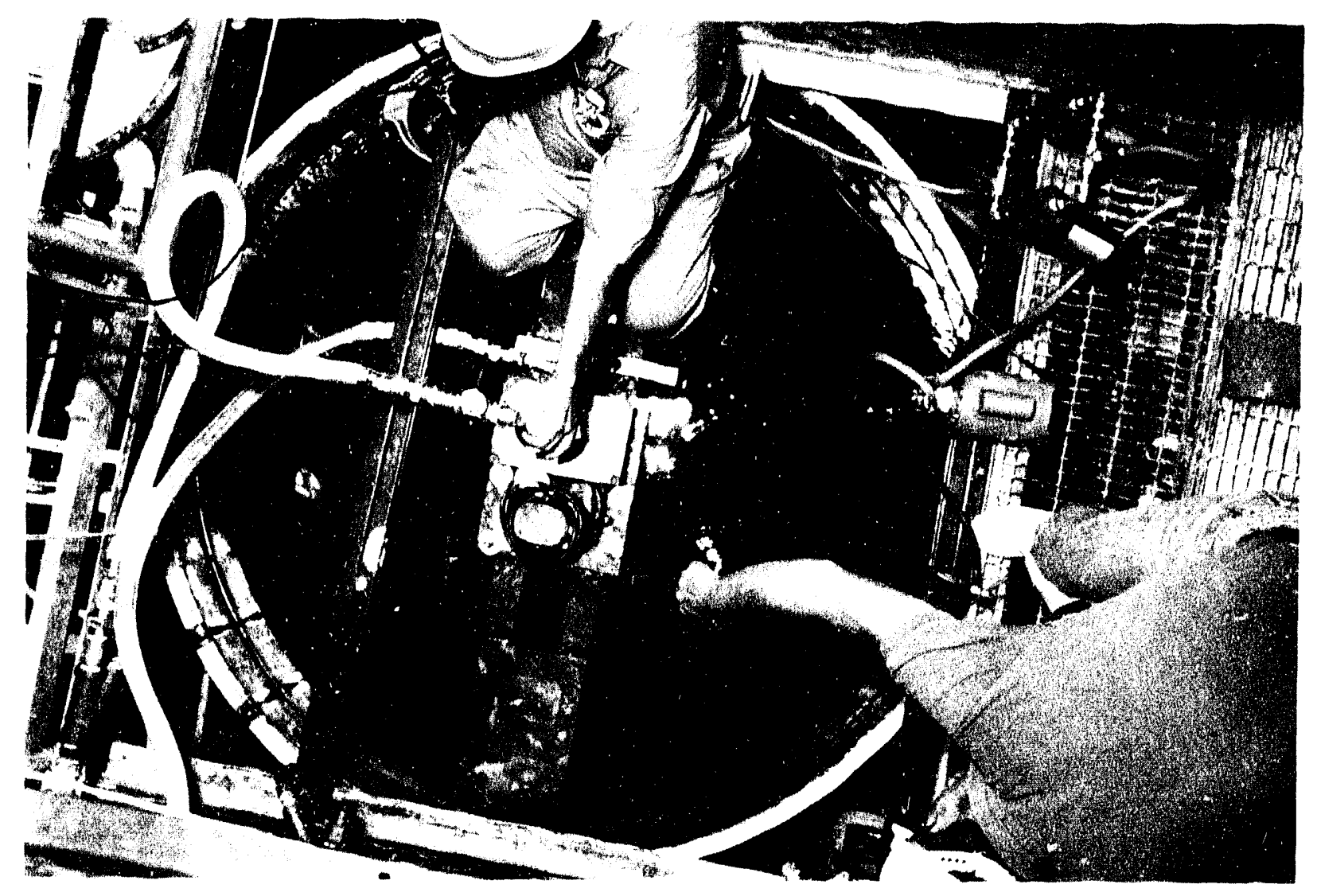

Figure 3.1. 1/12-Scale Tank with Mixing Pump Model 
The 1/12-scale mixing pumps model the operation of the prototype tank mixing pump in tank 241-SY-101. An assembly drawing of the model mixing pump is presented in Figure 3.2. To simulate the operation of the prototype mixing pump, a circulation pump draws the slurry from the upper portion of the tank and discharges it through the mixing pump model annulus out two diametrically opposed nozzles. The suction location can duplicate the same vertical location as the prototype mixing pump, but its horizontal position is slightly offset from centerline (approximately 2 in.). The nozzles are removable to accommodate design variations. A cross-sectional drawing of the nozzles used in the present tests is shown in Figure 3.3.

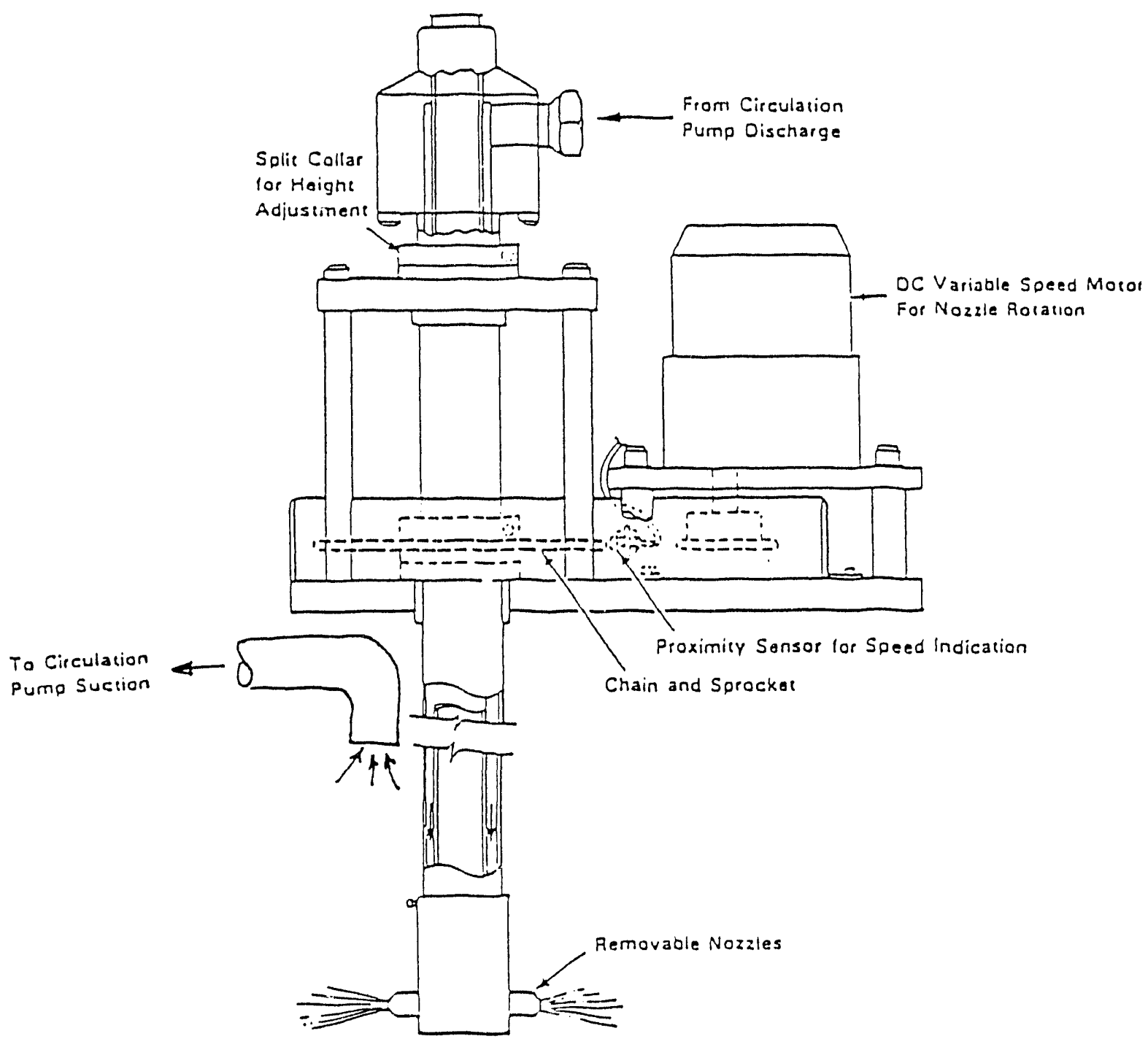

Figure 3.2. Mixing Pump Model Configuration 


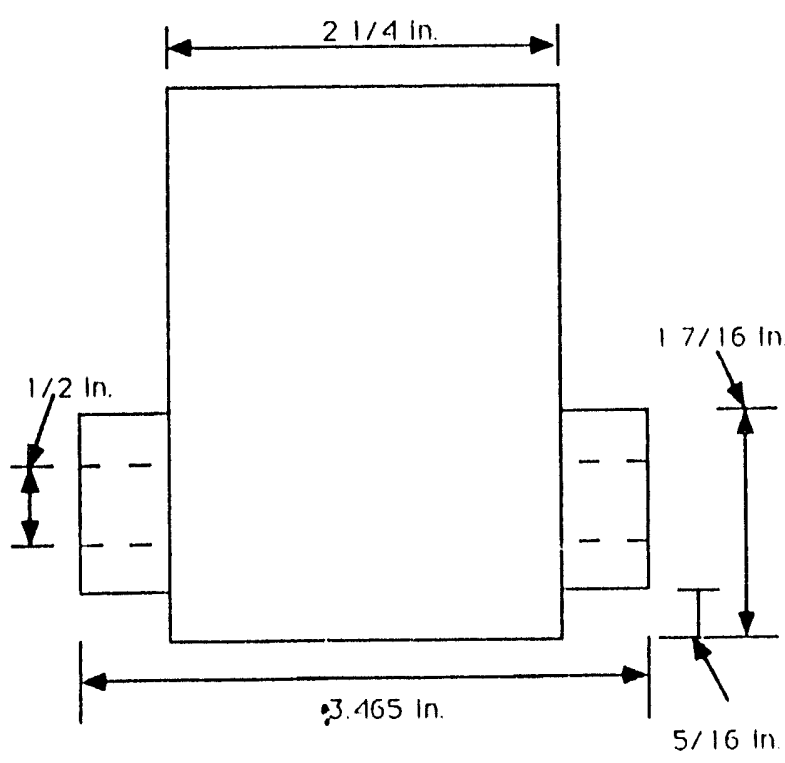

Dual Jet Nozzle

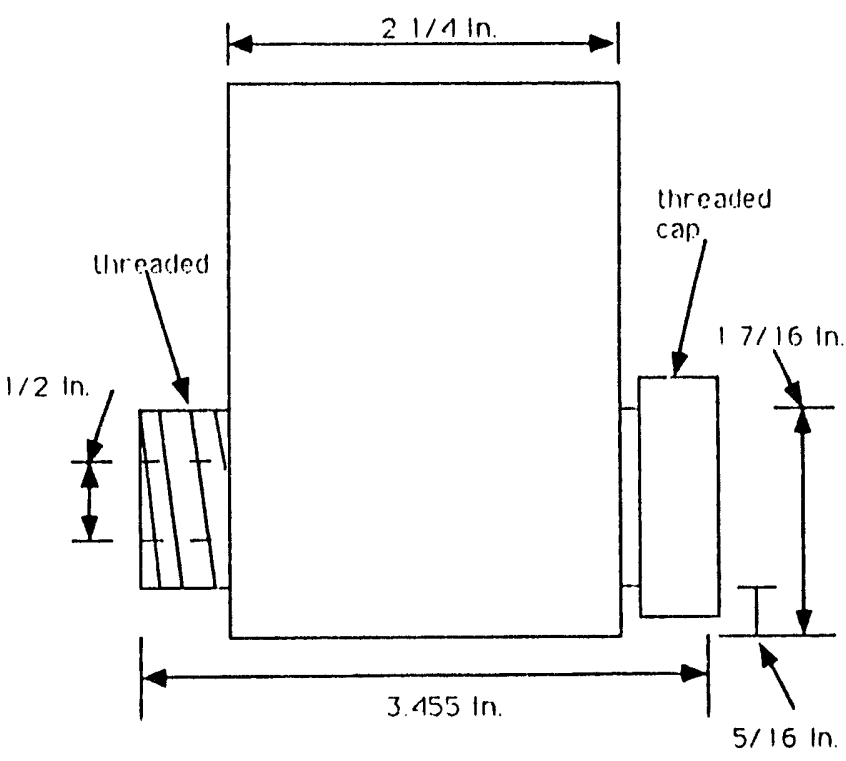

Single Jet Nozzle

Figure 3.3. Nozzle Cross Sections

The test facility can accommodate six mixing pumps, each with two nozzles. The circulation pump will deliver up to $25 \mathrm{gpm}$ at $207 \mathrm{ft}$ of head. The mixing height above the floor can be varied. Also, the mixing pump can rotate or oscillate at speeds up to $8 \mathrm{rpm}$. The facility is equipped to prepare waste simulants with components including makeup tank, holding tank, and circulation and transfer pumps. These components are shown along with manifolding and facility flow controls in Figure 3.4. The makeup tank is equipped with an agitator to mix the simulant prior to transfer to the scaled waste tank. The makeup tank is instrumented with load cells to measure slurry ingredients, as well as the mass of slurry transferred into and retrieved from the 1/12-scale tank. A centrifugal pump with a capacity of $50 \mathrm{gpm}$ at $50 \mathrm{ft}$ of head is used to transfer slurries throughout the test facility.

\subsection{Shear Vane Tank}

A cubical (1m x $1 \mathrm{~m} \times 1 \mathrm{~m})$ clear tank (hereafter referred to as the shear vane tank) was moved into the 336 Building and positioned as close as possible to the 1/12-scale tank. The shear vane tank was placed on grade level ( $12 \mathrm{ft}$. above) and to the north of the $1 / 12$-scale tank. This arrangement enabled measurement of, essentially, in-situ shear strength of the settled simulant without risking interaction between the mixing jet and the shear vane. The simulant was transferred between the $1 / 12$-scale and the shear vane tanks as originally mixed and subsequently re-mixed between tests. 


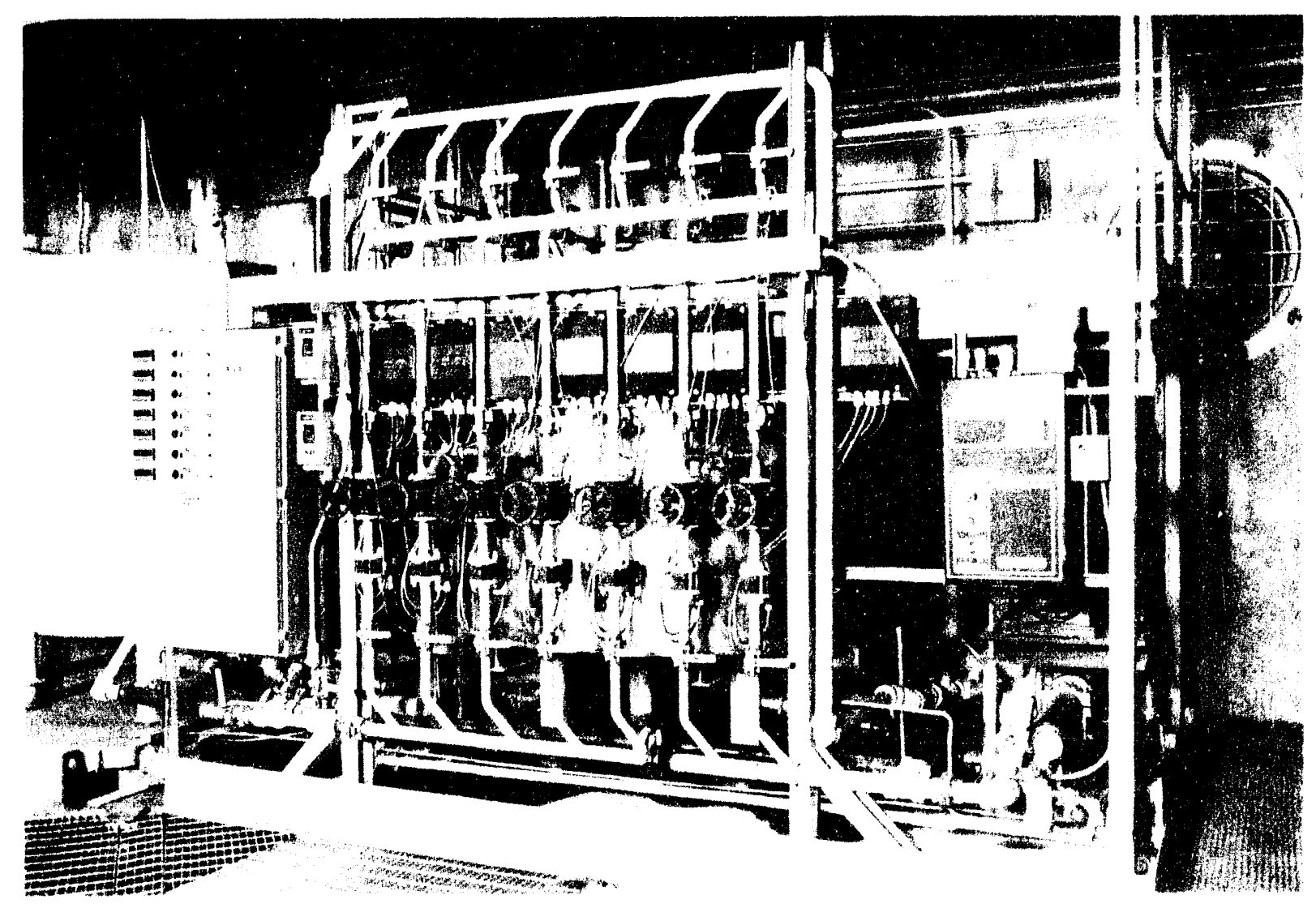

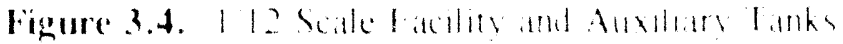

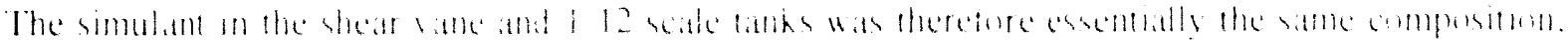

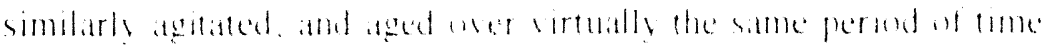

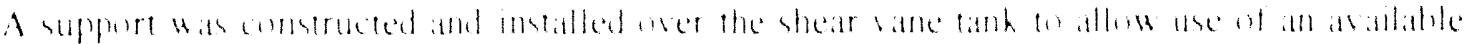

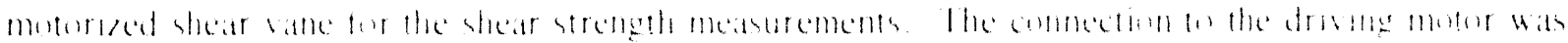

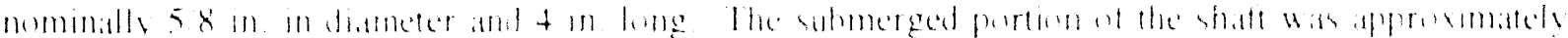

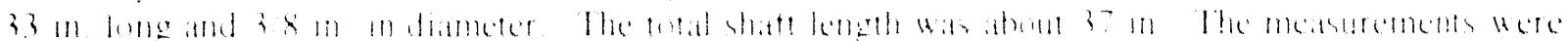

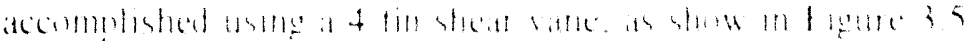




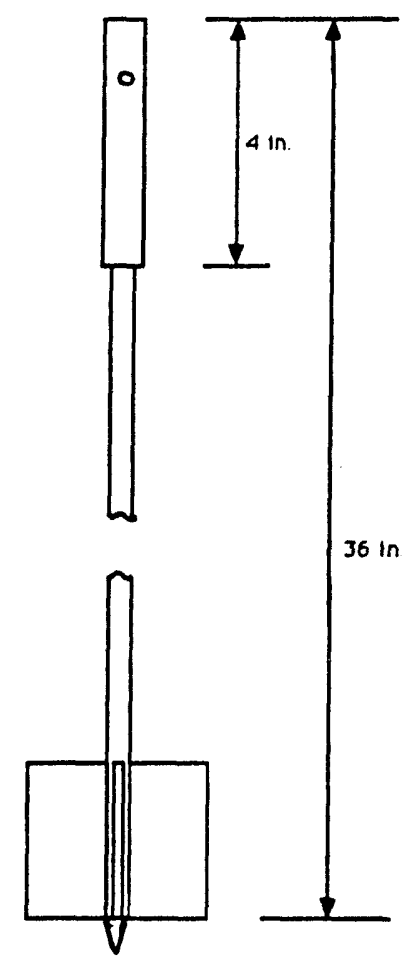

Figure 3.5. Shear Vane Schematic

Shear strength of the material was computed from the torque measured as the fins were rotated through the sample material. A fundamental assumption in the computation of shear strength is that the vane shears a cylinder of the sludge, Figure 3.6. The measured torque is the sum of the shear across the exposed surfaces of the cylinder: i.e. the top, bottom, and sides. The general expression for torque over the surface area of a cylinder is:

$$
T_{\text {meas }}=2 \pi t R^{2}(H+2 R / 3)
$$

where: $T_{\text {meas }}=$ measured torque

$\mathrm{t}^{\text {meas }}=$ shear strength

$\mathbf{R} \quad=$ radius of effective cylinder

$\mathrm{H} \quad=$ height of effective cylinder

For measurements performed in support of the tests reported here, $\mathrm{H}=2 \mathrm{R}$; therefore, Equation 3.1 reduces to the following:

$$
\mathrm{T}_{\text {meas }}=(16 / 3) \pi t R^{3}
$$




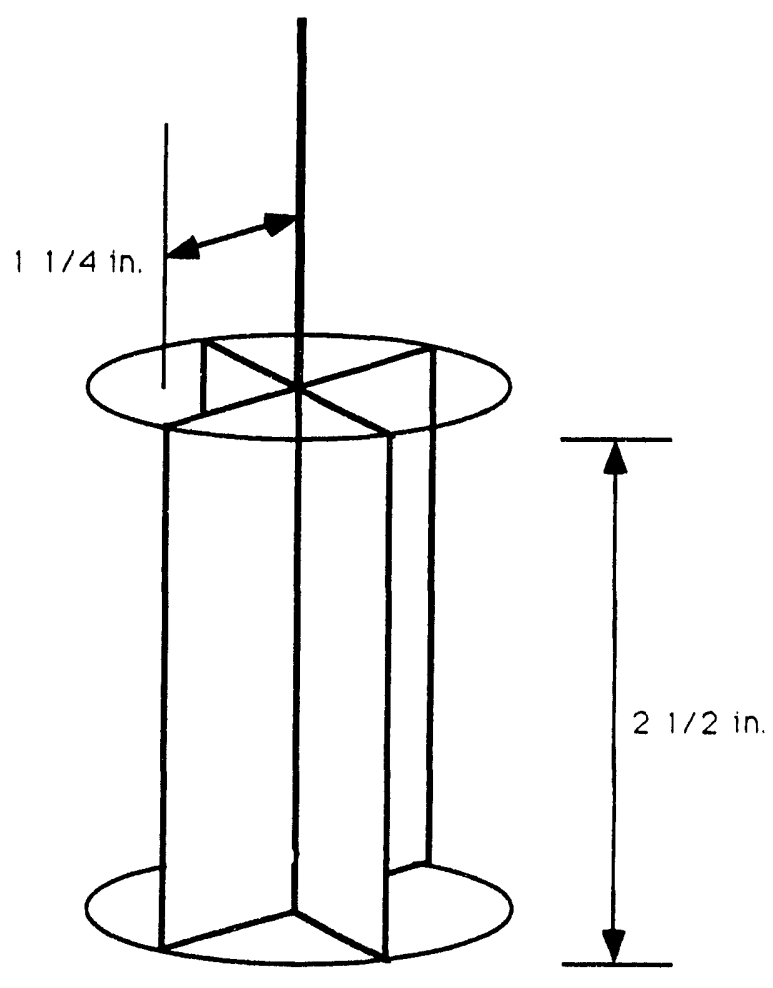

Figure 3.6. Shear Vane Fin Geometry

Rearranging to solve for the shear strength, $t$,

$$
t=\frac{3 T_{\text {meas }}}{16 \pi R^{3}}
$$

The shear vane, as received, was understood to be a completely functional unit. It was discovered, however, that the reducing gear was stripped and that the procedure accompanying the shear vane was in error. Once the failed component was replaced and the procedure corrected, the shear vane was operational and utilized to perform the in-situ torque measurements. 


\subsection{Instrumentation and Visualization Strategy}

The objective of the MIV and BPR tests was to obtain video records of the jet-sludge interface interaction. A related objective was to obtain limited semi-quantitative information from the video records. Measurements such as jet velocity, while desirable, require disturbance of the sludge by the placement of instrumentation probes in the sludge layer. The effect of probe installation disturbances could not be readily accounted for; therefore, one half of the tank (north) was left undisturbed before jet injection. All disruptive instrumentation probes were placed in the other half (south) of the tank. Division of the tank into pre-disturbed and undisturbed halves was implemented in the dual jet test.

\subsection{Process Measurement}

Total process flowrate supplied to the jet assembly was measured by a 1-in. Krohne electromagnetic flowmeter in the process line. The flowmeter was calibrated in place between 0 and $25 \mathrm{gpm}$. Two jet configurations were ultimately used in the tests discussed in this report: dual opposing jets and a single jet. During single jet tests, the measured flowrate corresponded directly to the jet flow. For the dual jet test, a direct measurement of the flow split between the nozzles was not possible with the existing setup; so it was assumed that the flow split equally between the two nozzles.

There was no active heat input to the test loop and the entire test loop and tank were allowed to equilibrate with the environment. Three grounded junction, sheathed, $1 / 16$ in., standard limits of error, type $\mathrm{J}$ thermocouples were installed in the $1 / 12$-scale facility. Two thermocouples were attached to the inside wall of the south east quadrant of the tank. One thermocouple was located in-line with the jet centerline, (nominally 3 in. from the bottom of the tank. A second thermocouple was attached 25 in. above from the first, or 28 in. from the bottom of the tank. The third thermocouple was installed through a fitting just upstream of the downward transition piece of the pump discharge line. Once the tank was filled with simulant, visual and physical access to the wall thermocouples was not possible. The reported thermocouple locations represent nominal position information, and it is possible that the thermocouple positions changed over the testing period.

Review of the video record for MIV \#1 highlighted the need for additional bleed capacity in the pump discharge line, to eliminate trapped air in the lines, which apparently resulted in undesirable (non-jet) disruption of the sludge. The maximum temperature difference observed for MIV \#1 $\left(2{ }^{\circ} \mathrm{C}\right)$ was not significantly different than the error limits for the thermocouples in use. Therefore, the thermocouple installed in the pump discharge line was replaced with a valve assembly, so that air could be bled from the line before turning on the pump. 


\subsection{Jet Velocity \& Jet Progress}

MIV and BPR tests were transient tests. Therefore, detailed steady-state jet velocity profiles were not obtained. The following measurements were planned for the dual jet MIV tests. It was postulated that the buoyant sludge created for the BPR test might be sufficiently unstable to preclude measurements that required insertion of probes into the settled sludge. Only one dual jet test was completed. The remaining tests were completed with a single jet and precluded use of the majority of the following instruments.

\subsubsection{Single Point Jet Velocity - Dual Jet Configuration Only}

Use of the insertion type magnetic flowmeter was limited to dual jet tests. The transient emphasis of the tests limited attempts at velocity measurement to the placement of the probe at a predetermined location downstream of the jet exit. The probe was in position while the solids were settling; hence the solids settled around the velocity probe. Placement of the probe was based on expected jet behavior, with no assumption that the placement was optimal.

An attempt was made to monitor the progress of jet burrowing with flow switches buried in the settled sludge at positions determined by expected jet behavior. The intent was to provide an indication (off/on) of the progress of the jet. The flow switch was a simple pendulum equipped with a LED and a computer compatible signal. The impinging jet velocity would cause the pendulum to deflect, the LED to illuminate, and the computer to register a signal change.

\subsubsection{Visualization Strategy}

The primary objective of the test was to obtain video records of the jet breaking through the settled sludge. To enhance the definition of the jet-interface, particles (acrylic plastic beads) were used to highlight the interface. A 4-in.-square grid was positioned over the north half of the tank to assist in quantifying the location of jet breakthrough.

The first video records were set up with two overhead video cameras which yielded plan views of the tank. One camera recorded events over the entire tank. The second was focused on the undisturbed, gridded (north) half of the tank. Subsequent video records were made using three video cameras, shown in Figure 4.1. Two cameras were placed as just described. The third camera was directed at an angle, and focused on the pump barrel and sludge layer. This angled camera typically provided the best view to estimate the time of jet-sludge interaction. 


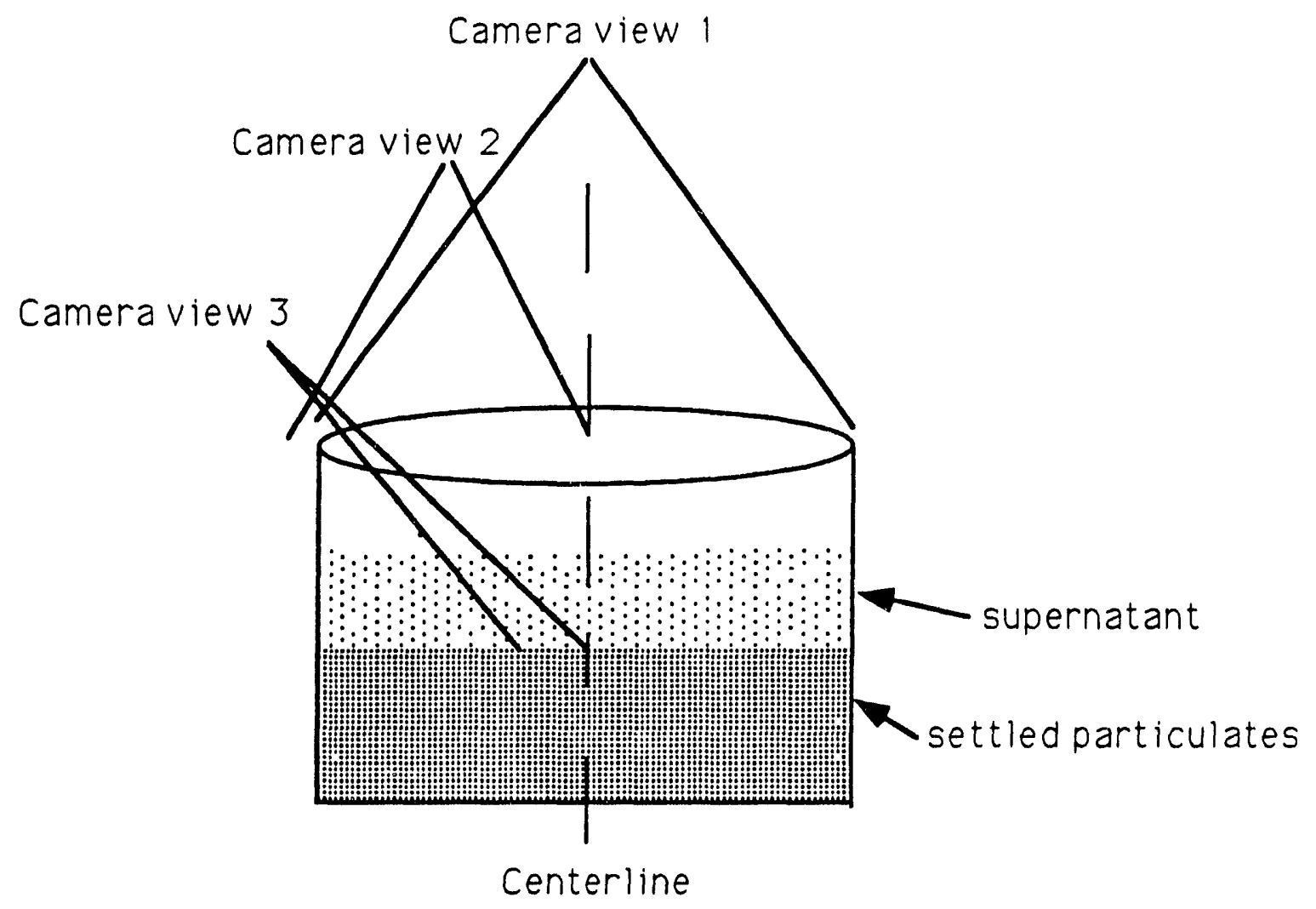

Figure 4.1. Camera View Schematic 


\subsection{Jet Nozzle Configuration and Placement Review}

Before testing started nozzle configuration and test conditions were reviewed to balance operational constraints and computational needs. The same jet and flow conditions were to be used for both the MIV and BPR tests. To create a test which could be modeled and computationally resolved, the jet diameter was re-evaluated. Modeling constraints included: turbulent jet; ratio of jet exit diameter to average jet exit velocity greater than $0.003 \mathrm{sec}$; and an estimated jet penetration length of 20 in. downstream of the jet exit.

\subsection{Jet Analysis Background}

Constraints on the sizing of the jet include the following; pump capacity limitations and the need for the jet at the exit to be turbulent (minimum Re of 30,000 using jet diameter, jet exit velocity, and supernatant density and viscosity). The penetration length of the jet was estimated using a Froude number analysis developed in (Abraham 1963). It was anticipated that the jet penetration length predicted by the Froude number analysis would exceed the actual penetration length. The fluid properties listed in Table 5.1 are based on previous work, and are not the results of the rheological measurements performed in support of the MIV/BPR tests.

\subsection{Estimate of Jet Penetration Length}

The approach described by (Abraham 1963) is summarized below:

- Compute densimetric Froude number for the nozzle

- Assume a sludge depth above the centerline of the discharge nozzle, e.g., 10 in. Compute the approximate non-dimensional height $(y / d)$ which corresponds to the height of the sludge layer above the centerline of the jet.

- Locate the non-dimensional height and estimated densimetric Froude number on Figure 3.2 of the reference, and read the estimated non-dimensional jet penetration and path length $(\mathrm{x} / \mathrm{d})$ and $(\mathrm{s} / \mathrm{d})$, respectively (Figure 5.1 shows the nozzle axes directions).

- Convert the non-dimensional values to desired linear dimensions.

Estimates of jet penetration length are presented in Table 5.2. 
Table 5.1. Jet Diameter Analysis Parameters

Supernatant viscosity, $\mathrm{v}_{\mathrm{su}}$

Supernatant density, $r_{\text {su }}$

Solids density, $r_{s}$

Sludge volume fraction solids

Sludge density @ 44\% solids, $\mathrm{r}_{\mathrm{sl}}$

Sludge depth

Maximum nozzle discharge

Reynolds number

Definitions:

Froude number

Reynolds number
$1 \mathrm{cP}$

$1 \mathrm{~g} / \mathrm{cm}^{3}$

$2.65 \mathrm{~g} / \mathrm{cm}^{3}$

$44 \%$

$1.73 \mathrm{~g} / \mathrm{cm}^{3}$

16 jet diameturs (minimum)

$15 \mathrm{gpm} /$ nozzle

$\geq 30,000$

$$
F I=\frac{u_{0}^{2}}{g d\left(r_{s 1}-r_{s u}\right)}
$$

(Abraham 1963)

$$
R e=\frac{u_{0} d r_{s u}}{v_{s u}}
$$

(Abraham 1963)

Jet exit diameter, $d$

Jet exit velocity, $u_{0}$

Jet diameter-exit velocity ratio

$$
C=\frac{d}{u_{0}}
$$

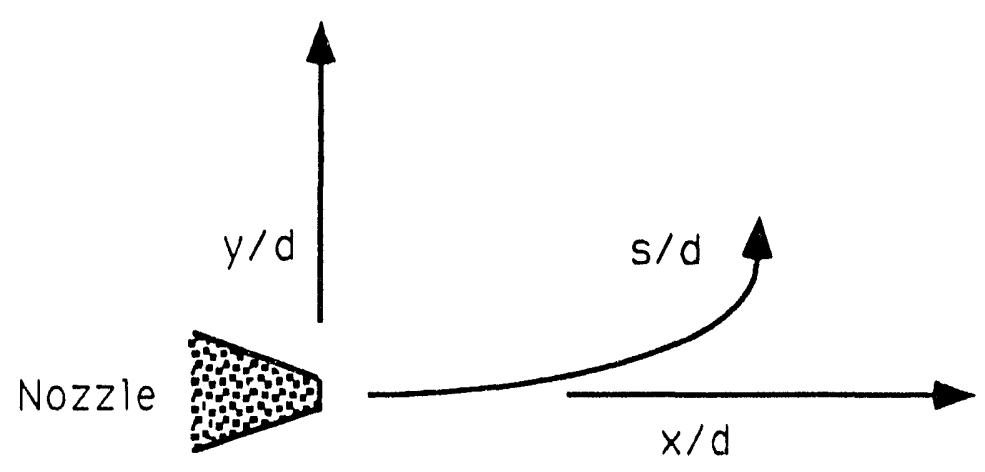

Figure 5.1 Nozzle Axes 
Table 5.2. Exit Nozzle Penetration Length

Case A

Nozzle diameter $=0.5$ in.; 10 inch sludge depth above jet centerline, $y / d=20$

\begin{tabular}{ccccccc}
\multicolumn{2}{l}{$\begin{array}{l}\text { Nozzle Discharge } \\
\mathrm{gpm}\end{array}$} & $\begin{array}{c}\mathrm{ft} / \mathrm{s} \\
\end{array}$ & $\begin{array}{c}\text { Approx Densimetric } \\
\text { Froude Number }\end{array}$ & $\frac{(\mathrm{x} / \mathrm{d})}{(\mathrm{s} / \mathrm{d})}$ & Approx (x) in. \\
10 & 16.3 & 275 & 43 & 53 & 21.5 \\
15 & 24.5 & 625 & 56 & 72 & 23
\end{tabular}

Case B

Nozzle diameter $=0.5$ in.; 15 inch sludge depth above jet centerline, $y / d=30$

\begin{tabular}{|c|c|c|c|c|c|}
\hline \multicolumn{2}{|c|}{ Nozzle Discharge } & Approx Densimetric & \multirow[b]{2}{*}{$(\mathrm{x} / \mathrm{d})$} & \multirow[b]{2}{*}{$(\mathrm{s} / \mathrm{d})$} & \multirow[b]{2}{*}{ Approx (x) in } \\
\hline gpm & $\mathrm{ft} / \mathrm{s}$ & Froude Number & & & \\
\hline 10 & 16.3 & 275 & 48 & 63 & 24 \\
\hline 15 & 24.5 & 625 & 66 & 77 & 33 \\
\hline
\end{tabular}

\subsection{Estimate of Time of Flight for Jet Penetration}

The time required for jet breakthrough can also be estimated from Abraham's work (Abraham 1963).

For the densimetric Froude number and (s/d) range applicable to this problem, rough estimates of the time of flight have been made. For a sludge depth of 15 in. an estimate of "average velocity" is $0.2\left(u_{0}\right)$ where $u_{0}$ is $16 \mathrm{ft} / \mathrm{s}$ and $25 \mathrm{ft} / \mathrm{s}$ (for 10 and $15 \mathrm{gpm}$ respectively). The maximum time of flight estimates are $0.8 \mathrm{~s}$ and $0.6 \mathrm{~s}$ for the $10 \mathrm{gpm}$ and $15 \mathrm{gpm}$ nozzle flow, respectively.

Jet diameter-exit velocity ratio and Reynolds and Froude numbers were computed for a range of nozzle diameters and flow rates using the preceding expressions. The jet penetration lengths were estimated using the approach described by Abraham. The results were reviewed and discussed with cognizant staff. It was agreed that the nozzle diameter for the MIV and BPR tests would be 0.5 in. and that the nominal flow rate would be $10 \mathrm{gpm} /$ nozzle.

The pump discharge was located in the center of the 1/12-scale tank. The jets were not rotated during the tests. The jet centerline was located $3 \frac{1 / 4}{\mathrm{in}}$. off the floor of the $1 / 12$-scale tank. The target depth of the sludge layer was a minimum of 16 jet diameters above the jet exit centerline. 


\subsection{Simulant}

Two simulant formulae were available for possible use in the MIV and BPR tests. Detailed discussion of simulant development is found in (Fort et al. 1993) and in (Liljegren 1993). The simulant constituents were water, sodium chloride, simple sugar, and silica flour (solids). Varying the amount of sugar in the formula yields simulants of different viscosities. The low-viscosity simulant was used in these tests because it provided a better defined interface and faster turn-around time, due to faster particulate settling than the high-viscosity simulant. Increasing the solids weight in the simulant formula was retained as an option to achieve the desired minimum 16 nozzle diameter (nominal 8 in.) sludge height above the nozzle centerline. The supernatant composition, Table 6.1, was not modified.

\subsection{Rheological Measurements}

Before the 1/12-scale testing began, the rheological properties of a bench-scale sample of the simulant were characterized. Density and viscosity measurements were made at increasing dilutions of supernatant in settled solids. Rheological testing provided the modeling staff with a curve describing the behavior of the simulant as a function of solids concentration, as shown in Figure 6.1 and Table 6.2.

The simulant used in rheological and scaled testing was, by weight: $63 \%$ water, $33 \%$ silica, $2 \%$ sugar, and $2 \%$ salt. The continuum liquid (supernatant) was, by weight: $94 \%$ water, $3 \%$ sugar, and $3 \%$ salt. Varying concentrations were created by mixing the same continuum mixture with the solids. Therefore, the weight percentage of all the constituents changes with particle concentration.

All testing was done at $73 \pm 2^{\circ} \mathrm{F}$. All rheograms were produced using a rotational viscometer. For mixtures with a solids volume fraction bounded by 0.03 and 0.30 , a capillary viscometer was used and no rheograms were produced.

Table 6.1. Low-viscosity Simulant Nominal Composition

\begin{tabular}{lrll}
\multicolumn{1}{c}{ Component } & & Wt $\%$ & Function \\
Minusil-30, silica & & $33 \%$ & solids \\
Sugar & $2 \%$ & supernatant \\
Salt $(\mathrm{NaCl})$ & $2 \%$ & supernatant \\
Water & $63 \%$ & supernatant
\end{tabular}




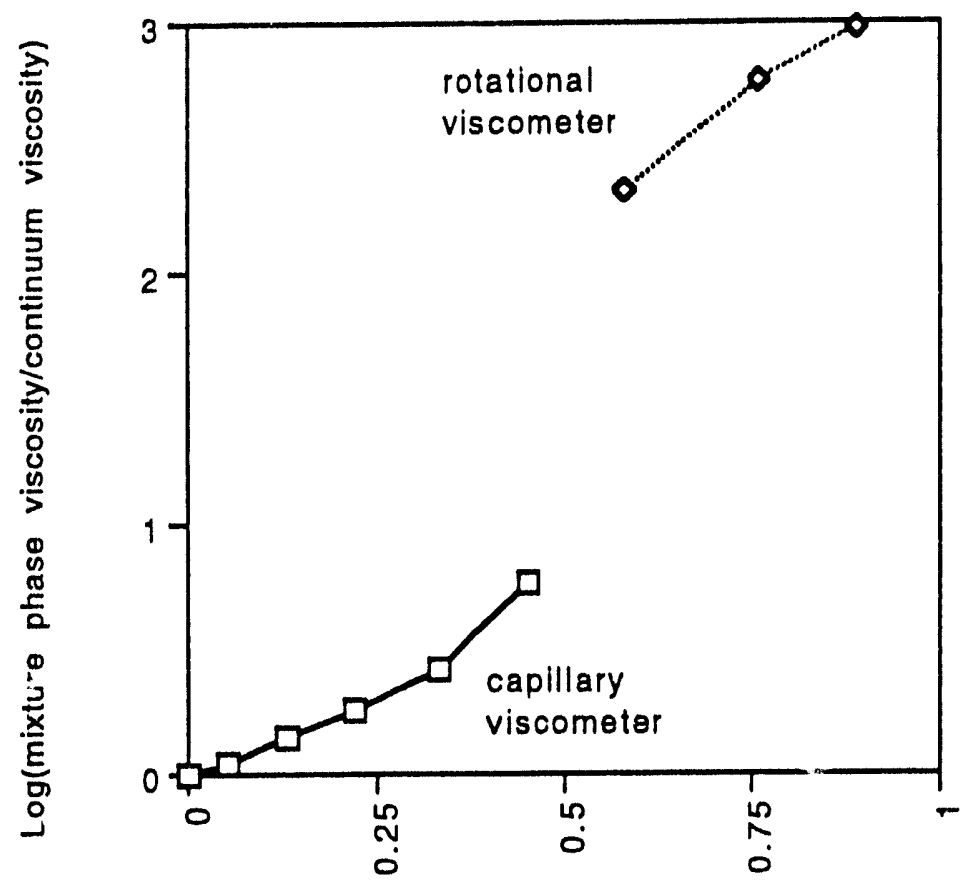

Normalized solids concentration

Figure 6.1. Simulant Relative Viscosity and Normalized Solids Concentration

The continuum (supernatant) liquid had a specific gravity of 1.03 and a viscosity of $1.2 \mathrm{cP}$. The presence of organics growing in the liquid had no measurable effect on the viscosity. The continuum liquid was tested over a strain rate of 0 to $300 \mathrm{sec}^{-1}$. The maximum packing fraction achieved by centrifugation was 0.59 .

Mixtures with solids volume fractions greater than 0.3 were tested by ramping the strain rate from 0 to $20 \mathrm{sec}^{-1}$ with a ramp time of 4 to $6 \mathrm{~min}$. The shorter the ramp time the greater the observed hysteresis. As the ramp time was increased, the sample tended to dry out before completion of the test. Therefore, samples were tested at optimum times which ranged from 4 to $6 \mathrm{~min}$. Viscosities were determined by applying a linear least squares fit to the data between strain rates of 5 and $20 \mathrm{sec}^{-1}$. All of the samples exhibited Newtonian behavior over this small range. The higher concentration mixtures also exhibited a significant, but unquantified, shear strength. 
Table 6.2. Simulant Relative Viscosity and Normalized Solids Concentĩation Values

\begin{tabular}{ccc}
$\begin{array}{c}\text { Normalized solids } \\
\begin{array}{c}\text { Concentrations } \\
\alpha \rho \alpha \mathrm{mp}\end{array}\end{array}$ & $\begin{array}{c}\text { Relative Viscosity } \\
\mu_{\mathrm{m}} / \mu_{\mathrm{c}}\end{array}$ & $\begin{array}{c}\log (\text { Relative Viscosity) } \\
\log \left(\mu_{\mathrm{m}} \mu_{\mathrm{c}}\right)\end{array}$ \\
\cline { 2 - 3 } 0 & 1 & 0 \\
0.05 & 1.1 & 0.0414 \\
0.13 & 1.4 & 0.145 \\
0.22 & 1.8 & 0.255 \\
0.33 & 2.6 & 0.415 \\
0.45 & 5.8 & 0.763 \\
0.58 & 216 & 2.33 \\
0.76 & 587 & 2.77 \\
0.89 & 957 & 2.98
\end{tabular}

$\alpha m p$ - Maximum packing fraction (void fraction) of solids; centrifuged 0.59

ap - Solids volume fraction

$\mu_{\mathrm{c}} \quad$ - Continuum viscosity (supernatant liquid); $1.2 \mathrm{cP}$

$\mu_{m}$ - Mixture viscosity 


\subsection{Buoyant Sludge Development}

The primary objectives of the BPR test were to 1) develop a repeatable, cortrollable method by which the simulant sludge could be made buoyant, i.e. a representation of trapped gas, and 2) obtain a video record of the mixing jet-buoyant sludge interaction.

To create a buoyant sludge, efforts focused on identification of buoyant particles that could be inserted and retained in the settled particulate (sludge) layer of the waste simulant. Injection of a gas into the simulant sludge could be a more realistic representation of the conditions in SY-101. The physics of rising compressible bubbles are not, however, currently included in the predictive model. Therefore, inducing buoyancy by injection of a gas was not a requirement for model prediction and comparison with observations. Unlike the MIV test, development of the strategy to create a buoyant sludge required bench scale work. Characteristics such as retention and stability were evaluated in bench scale tests. A strategy for incorporating the selected particles into a larger scale tank was also developed. The BPR test was not completed in the 1/12-scale facility because of the decision to repeat the MIV test with a single jet.

\subsection{Buoyant Sludge Development}

A characteristic which the buoyant sludge did not need to satisfy was the behavior of a compressible fluid during release. Specifically, the material added to create the buoyancy was not required to expanded on rising. Based on actual gas release volumes in the nominal range of 6,000 to $12,000 \mathrm{ft}^{3}$ and an estimated sludge volume of $61,000 \mathrm{ft}^{3}$, the volumetric percent of gas (voids) in the tank SY-101 sludge ranges from $10 \%$ to $20 \%$. The intent of the BPR was to provide a known initial condition against which model predictions could be compared. It was not the intent to duplicate the conditions or behavior in tank SY-101. It was, however, desirable to retain a relationship to tank SY-101 characteristics. Therefore, for development purposes, the target value range was selected as 10 to $20 \%$ voids (percent volume basis). Table 7.1 lists the number of various sized spheres required to create a nominal $20 \%$ void fraction in 29,452 in $^{3}$ of $1 / 12$-scale simulant sludge (sludge cylinder 75 in. in diameter by 13.5 in. high).

The quantity of spheres required is not trivial. Given the scheciule and resource constraints, it was preferred to identify and use material which could be readily obtainied in relatively large quantities.

Initial material reviews focused on plastics having a specific gravity close to 1 or slightly less, i.e., at a minimum neutrally buoyant in water. Spheres of candidate plastic materials sank in water and would not provide the needed buoyancy, and were set aside as candidates. The most positive results in a sample of simulant were obtained using common fishing line floats, ping pong balls, and hollow plastic golf balls. It was demonstrated that the floats and rigid hollow balls (ping pong and plastic golf balls) could be inserted into and retained by the simulant sludge. Based on the availability and the preference to handle as few particles as possible, the rigid hollow balls were selected as the 
Table 7.1. Number of Spheres to Create $20 \%$ Void Fraction $\left(29,452\right.$ in $^{3}$ of sludge)

\begin{tabular}{ccrr}
$\begin{array}{c}\text { Sphere Radius } \\
\text { in. }\end{array}$ & $\begin{array}{c}\text { Sphere Volume } \\
\text { in }^{3}\end{array}$ & & $\begin{array}{r}\text { Number for } \\
20 \% \text { Void }\end{array}$ \\
\cline { 1 - 1 } 0.25 & 0.065 & & 453,108 \\
0.5 & 0.524 & & 56,206 \\
1 & 4.189 & & 7,031 \\
2 & 33.5 & 879
\end{tabular}

buoyant particles. A mix of colored ping pong and white plastic golf balls were to be used to create the buoyant sludge. A maximum of $19 \%$ void fraction was achieved using rigid hollow spheres in a sample of sludge.

Low-viscosity simulant was prepared for the shear-vane tank in an effort to repeat the relatively high void percent as well as to refine the insertion procedure, before committing to a $1 / 12$-scale test. This final development test could not be completed before the start of 1/12-scale testing because the sludge layer did not develop enough strength to retain a golf ball in the time available.

\subsection{Suggested Buoyant Sludge Procedure}

The following is the proposed, though untested, strategy to create a buoyant sludge in the 1/12-scale facility. After completion of a MIV test, the contents of the tank are to be completely remixed and allowed to resettle. Periodically, the retention capability of the sludge will be checked by simply pushing a few golf balls into the sludge and observing whether the balls are retained or released. Once the balls are retained for at least 24 hours, efforts will be made to incorporate the balls into the entire 1/12-scale sludge layer. Briefly, the steps are conceptualized as follows:

1. Remove the supernatant from the 1/12-scale tank; very little residual should remain.

2. In one quarter of the tank, place a pro-rated portion of the estimated number of balls on the surface of the sludge. Using a large shovel, turn the sludge over, thereby incorporating the balls into the sludge. It is preferred that the balls be uniformly distributed throughout the sludge. Add and turn over additional balls until the desired number have been incorporated into the tank section. Move on to the next tank section and repeat the incorporation steps. Remove and count the balls that were not incorporated into the sludge. Determine the number of balls successfully added to the sludge layer.

3. Place a thick and oversized plastic sheet over the top of the sludge layer. The sheet should have tails sufficiently long to enable lifting of the plastic sheet out of the tank. Slowly and carefully, begin to return the supernatant to the 1/12-scale tank. Once enough supernatant has been returned to the tank so that completion of the transfer will not disturb the sludge, the plastic sheet can be removed. Continue the transfer of the supernatant back to the $1 / 12$-scale tank. 
4. On completion of the transfer, remove the plastic sheet if it was not removed earlier. Remove and count the balls that have floated to the surface. Allow a minimum of 12 hours of additional settling before running the BPR test.

5. Remove and count any of the balls that are released before the completion of the BPR test. 


\subsection{Test Descriptions and Results}

Ultimately, three tests (video records) and one observation were completed under this test program and are individually described in the following section. A single batch of simulant was used to complete the tests. As stated previously, the buoyant particle release (BPR) test was not attempted at $1 / 12$-scale. The 1/12-scale BPR test was set aside after review of the video record from the first MIV test by the modeling and experimental staff. To respond to concerns regarding jet discharge symmetry and questions relative to the jet progression within the sludge, the MIV test was repeated. Results of the video record review and shear strength measurements are included in the following discussions. Table 8.1 lists the chronology of simulant preparation and testing in the $1 / 12$-scale facility.

\subsection{General Test Outline}

Each test discussed in the following subsections shared a common set of general preparatory steps. The simulant for each test was thoroughly mixed on a Friday, with the test performed on the following Wednesday. Simulant settling time was nominally equal for each of the tests. The lines of the loop were left as full as possible to minimize the amount of air in the loop lines.

Supernatant clarity and the control of organic growth were of concern between initial mixing and completion of the test runs. Chlorine levels in the 1/12-scale and shear-vane tanks were monitored and adjusted using standard swimming pool techniques. Eventually, a common pool algicide was added in an effort to control the organic bloom. Once initial settling was complete, a swimming pool filter was activated in an effort to achieve and maintain supernatant clarity in the $1 / 12$-scale tank. The filter was equipped with a fabric diffuser bag installed on the discharge to prevent the discharge jet from disturbing the sludge layer. A small pump-cartridge filter assembly was utilized for active filtration of the shear-vane tank. Every effort was made to treat and handle the simulant in the

Table 8.1. Chronology of $1 / 12$-Scale Testing

\begin{tabular}{|c|c|}
\hline Date & Event \\
\hline April 9, 1993 & Simulant Preparation \\
\hline April 13, 1993 & Supernatant Replacement \\
\hline April 14, 1993 & MIV \#1, dual jet \\
\hline April 16, 1993 & Simulant Remix \\
\hline April 23, 1993 & Simulant Remix, nozzle replacement \\
\hline April 28, 1993 & MIV \#2, single jet \\
\hline April 30, 1993 & $\begin{array}{l}\text { MIV \#3 Observation, single jet } \\
\text { Simulant Remix }\end{array}$ \\
\hline May 5, 1993 & MIV \#4, single jet \\
\hline
\end{tabular}


1/12-scale and shear-vane tanks equally. As appropriate, other preparatory work, such as data acquisition system modifications was completed before test day.

On the morning of the test, the filter was shut down and the diffuser bag was gently removed from the tank. The location grid was installed and the interface was seeded, by hand, with interface particles that had been placed in a bucket of supernatant the previous night. At the same time, the cameras were set up and the monitor images were assessed. The test phase commenced with the start of the data acquisition log and energization of loop equipment. Time zero of the test was assigned to the time at which the pump was started. The tests were terminated based on loop status or time. In all video record cases (MIV \#1, \#2, and \#4), the intent of observing the initial phase of jet-sludge interaction was satisfied. Shear strength measurements were made in the shear-vane tank on the same day, generally after completion of the 1/12-scale test. Shear-vane measurements are presented and discussed in Section 8.6.

\subsection{Mixing Interface Visualization (MIV) Test \#1}

The low-viscosity simulant was originally mixed on April 9, 1993. It was necessary to decant and replace the supernatant on Tuesday, April 13 because of an organic bloom. Organic growth within a period of 7 to 14 days has been observed before and resulted in the original plan to complete the tests back to back over a two week period. Recognizing the potential of organic growth, the 1/12-scale facility was filled and lines circulated with chlorinated water. The loop was left filled with the chlorinated water for 2 days. Before simulant mixing, the chlorinated water was flushed out of the loop. The occurrence of an organic bloom within a few days of simulant mixing had never been observed before. Subsequent to replacement of the supernatant, the chlorine level of the supernatant in the 1/12-scale and shear-vane tanks was monitored and adjusted, using standard swimming pool techniques in an effort to minimize organic growth. Active filtration was employed to clarify the supernatant before testing. This consisted of a swimming pool filter equipped with a discharge diffuser bag in the 1/12-scale tank, and a small pump-cartridge filter for the shear-vane tank.

MIV \#1 was a dual jet test and therefore the insertion electromagnetic flow meter and flowswitches were installed as described in Section 5.1. All inserted probes, including the two tank wall thermocouples were placed in the south half of the tank. The north half of the tank was left undisturbed. Nominal locations of the insertion electromagnetic flowmeter (EMF) and flowswitches are listed in Table 8.2 and shown in Figure 8.1. The thermocouples were installed before simulant preparation and the EMF was inserted just after simulant preparation. Flowswitches were installed approximately twelve hours before testing.

MIV \#1 was completed on Wednesday, April 14, with a two-video-camera set-up. One camera provided a plan view of the entire tank. The second camera provided a plan view of the north half of the tank. The clarity of the supernatant was good. Conditions of the test are summarized in Table 8.3.

Eight seconds after the pump was started, bubbles (air from discharge line) were visible on the south side of the tank. Bubbles carry up fines from the interface, and lead to quick obscuration of the supernatant. Relatively few bubbles were expelled in this case, and the interface remained fairly clear 
Table 8.2. Nominal Location of Instrumentation Probes for MIV \#1

Instrument

Insertion electromagnetic flowmeter

Flowswitches \#1 \& \#2

Flowswitch \#3

Flowswitch \#4
Location

$14 \frac{1}{1 / 2}$ in. from jet exit

$31 / 4$ in. above tank floor

$181 / 4$ in. from jet exit

$4 \frac{1}{2}$ in. to east from jet centerline

$31 / 16$ in. above jet centerline

$271 \frac{1}{4}$ in. from jet exit

$65 / 8$ in. to east from jet centerline

$53 / 4$ in. above jet centerline

$281 / 4$ in. from jet exit

$6 \frac{5 / 8}{8}$ in. to west from jet centerline

$53 / 4$ in. above jet centerline

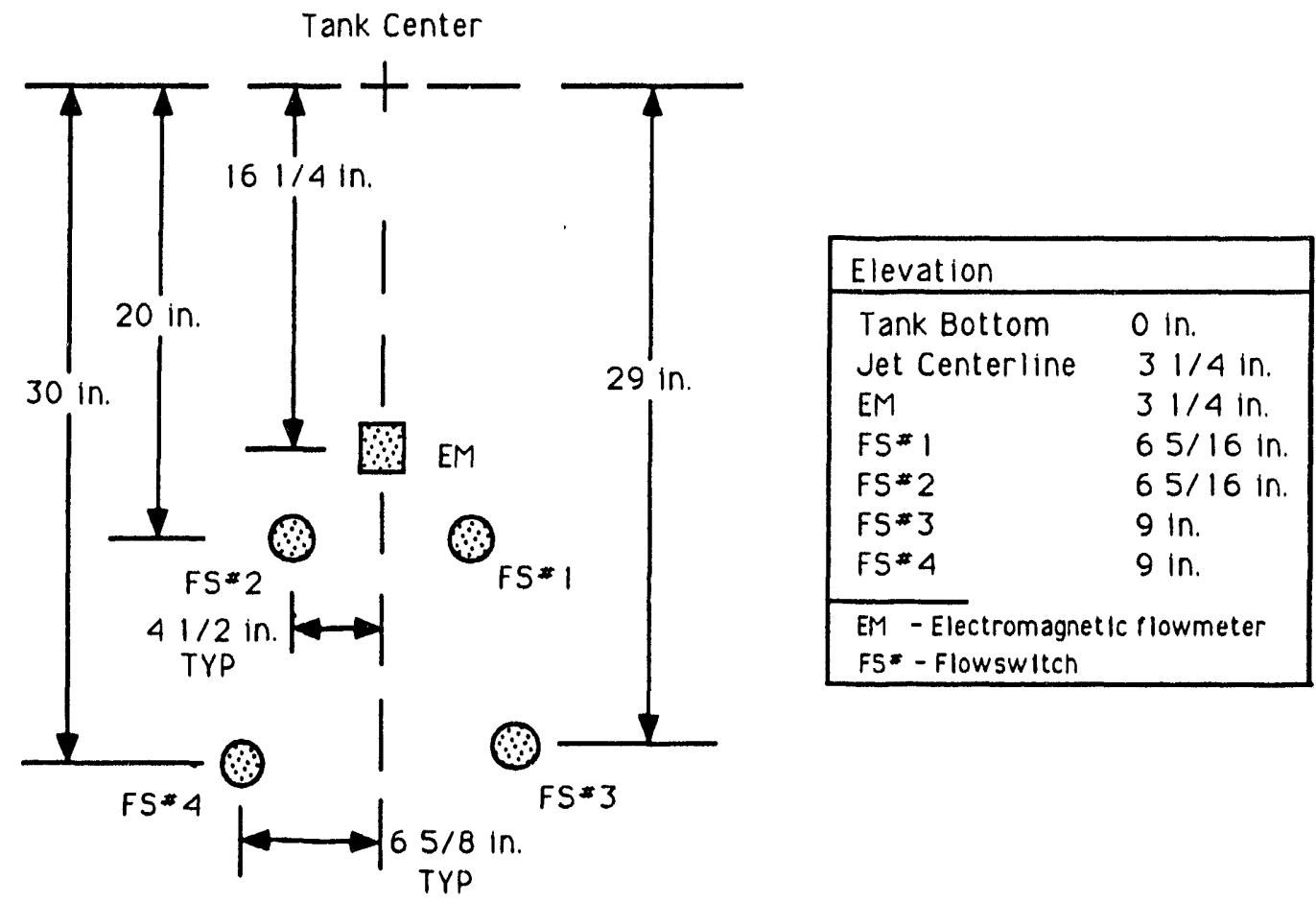

Figure 8.1. MIV \#1 Instrumentation Locations, Plan View 
Table 8.3. Conditions for MIV \#1

$\begin{array}{ll}\text { Jet Configuration } & \text { dual } \\ \text { Total flow rate } & 20 \mathrm{gpm} \\ \text { Flow rate per jet } & 10 \mathrm{gpm} \\ \text { Maximum Pressure before } & 42 \mathrm{psi} \\ \text { breakthrough (indication) } & \end{array}$

throughout the test. The run was terminated after approximately ten minutes because interface tracer particles were captured in the pump suction line, and eventually blocked a narrow section of the discharge line. The blockage was subsequently cleaned out and a strainer was placed over the pump suction line to prevent blockage in future tests. The flowswitches did not trip during the test. Either the flowswitch disks were not placed so that they were :xposed to the jet; or the observed adhesion of balls of sludge ( 2 to 3 in. in diameter) around the flat isk of the flowswitch prevented its activation.

\subsubsection{Measurement Results for MIV \#1}

Time history of the three monitored temperatures is presented in Figure 8.2. After pump operation began (at 0 minutes), the variation between all three temperatures was approximately $2^{\circ} \mathrm{C}$. An

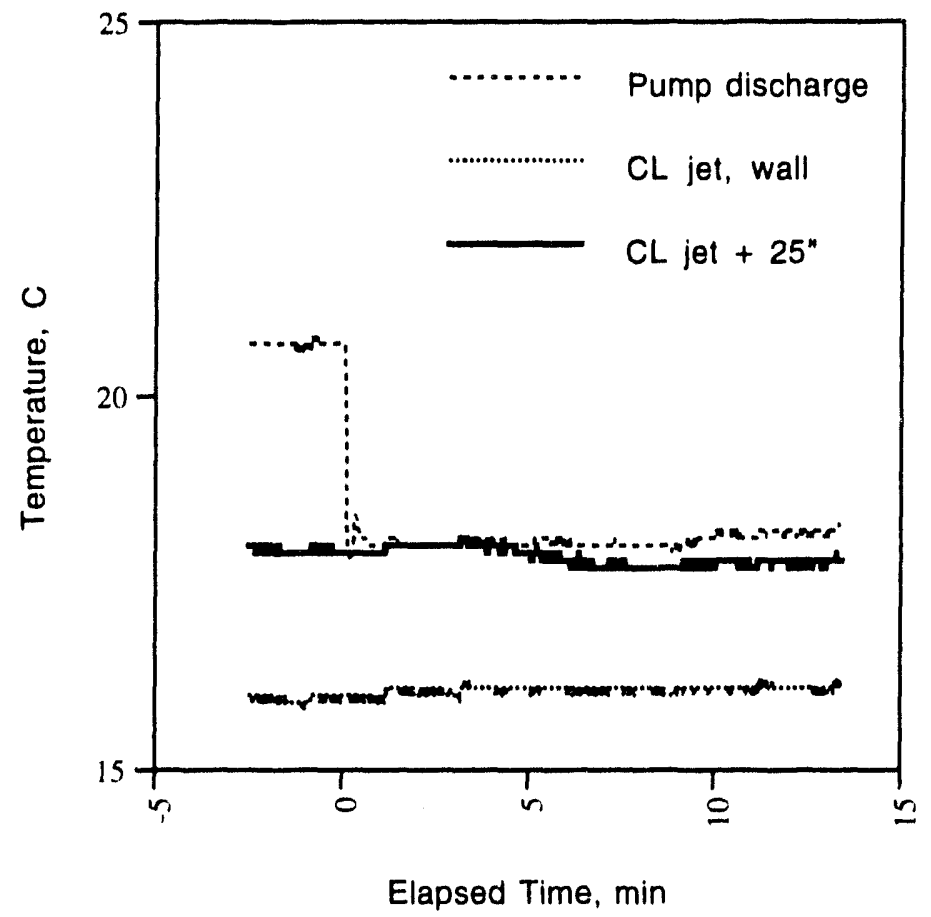

Figure 8.2. MIV \#1 Temperature 
accepted value for the standard limit of error, type $\mathrm{J}$ thermocouples is $2^{\circ} \mathrm{C}$. A difference of $2{ }^{\circ} \mathrm{C}$ between thermocouples is not necessarily indicative of a temperature difference. MIV \#1 was therefore, essentially, isothermal.

The process flow measurement time history is presented in Figure 8.3. The total flow was $20 \mathrm{gpm}$ (measured) which was assumed to yield $10 \mathrm{gpm} / \mathrm{jet}$. Flow rate delivery was constant at a nominal $20 \mathrm{gpm}$ throughout the duration of MIV \#1. The flow spike at approximately one minute before test initiation has not been attributed to a specific action or event associated with this test.

Uncovering of the insertion type electromagnetic flowmeter (EMF) by jet action can be seen in Figure 8.4. Though the EMF signal has a tendency to be noisy, a definite increase in velocity is seen at approximately 5 minutes into the test. The EMF signal continues to increase during the test to a maximum of approximately $2.5 \mathrm{ft} / \mathrm{sec}$, then drops in response to the pump shutoff at approximately 10 minutes.

Observations made the day after the test corroborate the test observation that the jet burrowed farther on the south side of the tank than it did on the north side. Among the possible explanations for that observation are 1) insertion of the instrumentation probes disrupted the structure of the settled sludge layer and reduced the strength of the material in the south half of the tank; or 2) the flow out of the jets was asymmetric, with more flow passing through the south jet than the north jet. Given that the jet nozzles are identical, it is asserted that the distance discrepancy between the north and

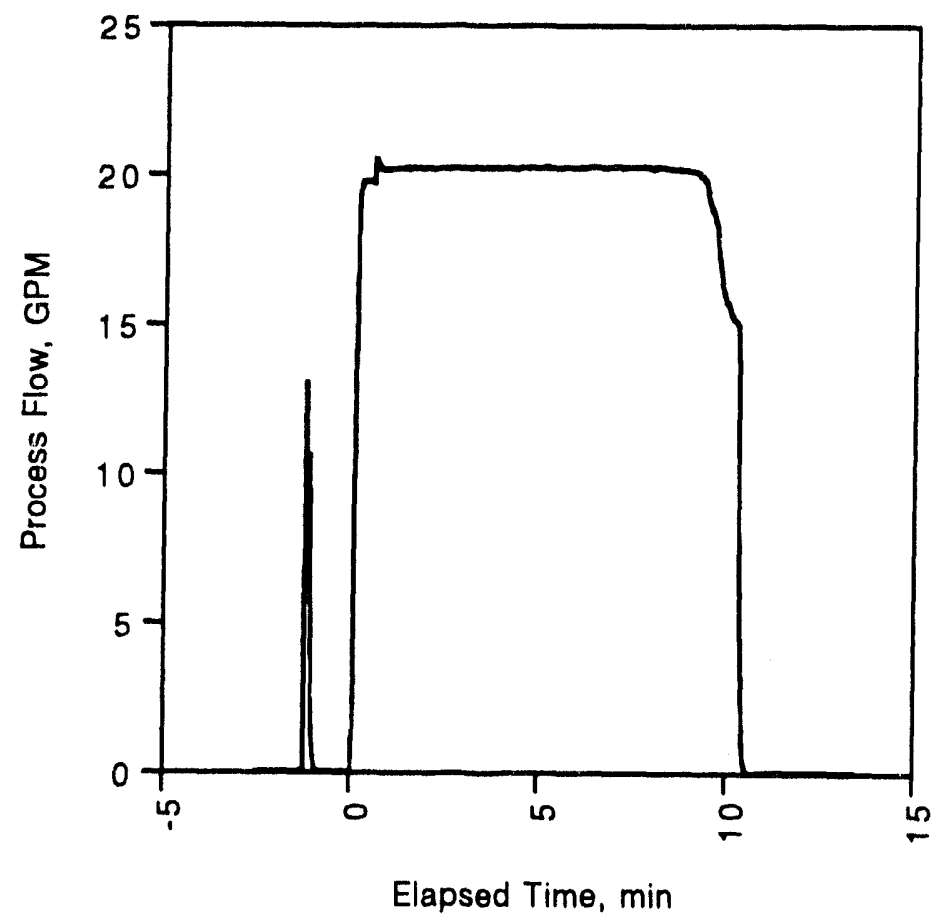

Figure 8.3. MIV \#1 Process Flow 


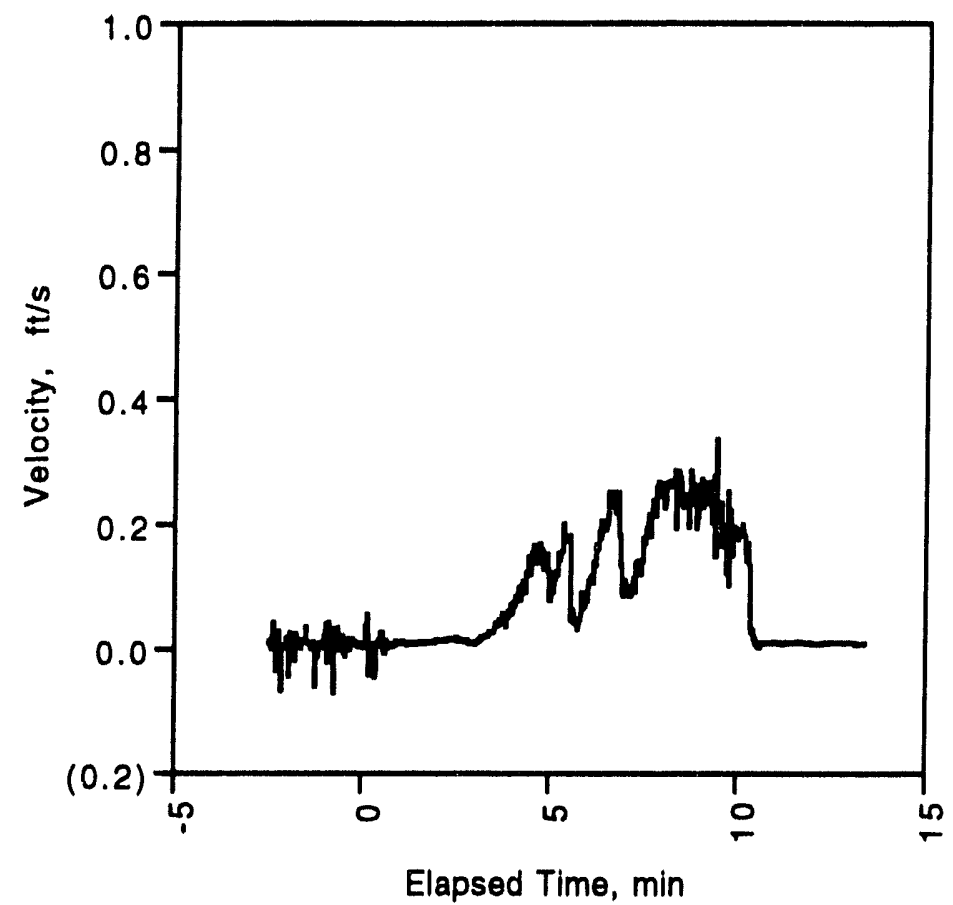

Figure 8.4. MIV \#1 Buried EMF Probe Response

south halves of the tank is attributable to the disruption of the sludge structure in the south half of the tank. It was interesting to note the clear pattern of burrowing evident in Figure 8.5. The height of the sludge ledge demarcating the edges of the jet disturbed area was approximately 2 to 3 in.

Estimates of the location of the jet at various elapsed times after pump initiation were obtained by review of the videos and estimating distances as best as possible. Each observation was timed by a stop clock whose zero was pump initiation. Summaries of the jet location and the interface (distance from the air-supernatant surface to the supernatant-sludge surface) are presented in Tables 8.4 and 8.5.

The difference between the burrowing characteristics of the jet in the north and south sections can be attributed to the weakening of the sludge structure by probe insertion and not to an unequal flow split. Measuring the flow split could not be accomplished within the constraints of the test program. Therefore, it was decided to conduct additional single jet MIV test(s) at the expense of completing the BPR test. Use of a single jet precluded the continued use of the buried EMF and flowswitches. To accomplish the single-jet test, a new pump end cap having the capability to act as a single or double jet was fabricated, the pump discharge was removed, the new cap was installed, and the pump model was re-installed in the tank. Cap replacement operations had to be accomplished within an hour or so after remix of the simulant and had to be performed "blind", i.e., the position of the re-installed discharge leg could not be measured directly. Every effort was made to ensure 

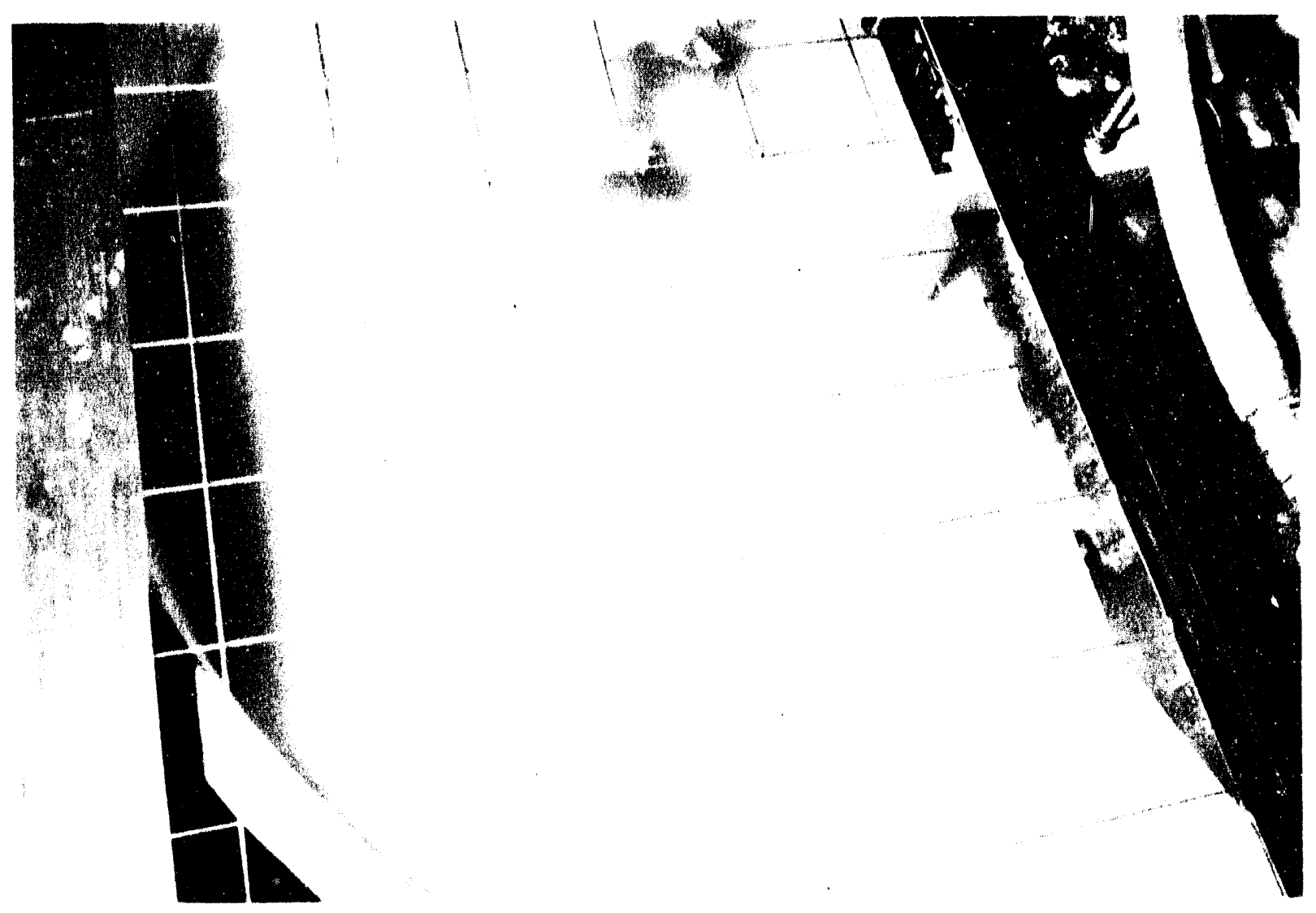

Figure 8.5. Post MIV \#I Burrowing Pattern on North Side

Table 8.4. MIV \#I Jet-Progression Table

\begin{tabular}{|c|c|}
\hline Time & Location \\
\hline (Os & na \\
\hline $121 \mathrm{~s}$ & $\begin{array}{l}139 / 10-14 \%, \mathrm{~N} \\
11 / 3 \mathrm{~W}\end{array}$ \\
\hline 1.55 & $\begin{array}{l}15 \%-16 / 4 \mathrm{~N} \\
-1 \% \mathrm{~W}\end{array}$ \\
\hline 251 & $\begin{array}{l}19 \%-20 \% \mathrm{~N} \\
-3 \%, W\end{array}$ \\
\hline 394 & $\begin{array}{l}-21 / 10-22 \mathrm{~N} \\
0 \mathrm{~W}\end{array}$ \\
\hline 4.59 & $\begin{array}{l}-23 \% / 10-24 \mathrm{~N} \\
-14 / 3 \mathrm{E}\end{array}$ \\
\hline
\end{tabular}


Table 8.5. Interface Location for MIV \#1

\begin{tabular}{|c|c|}
\hline $\begin{array}{l}\text { Time } \\
(\mathrm{sec})\end{array}$ & $\begin{array}{l}\text { Interface Distance } \\
\text { Below Surface (in) }\end{array}$ \\
\hline 0 & $20 "$ \\
\hline 251 & $\begin{array}{l}\text { 12" (estimated from written } \\
\text { log and video) }\end{array}$ \\
\hline 331 & $10^{\prime \prime}$ \\
\hline 397 & $8 "$ \\
\hline 586 & $43 / 4 "$ \\
\hline 618 & pump off \\
\hline 694 & $4^{1 / 2}{ }^{\prime \prime}$ \\
\hline
\end{tabular}

accurate re-installation of the discharge leg. To assist in maintaining the tank contents in suspension while the nozzle was replaced, a flexible hose replaced the discharge leg and was moved manually throughout the tank. To provide additional venting capability to the loop, the pump discharge thermocouple was replaced by a valve assembly.

\subsection{Mixing Interface Visualization (MIV) Test \#2}

A delay in the testing schedule, caused by having to fabricate a single nozzle jet, required that the simulant be remixed on April 16 and April 23, 1993. MIV \#2 was scheduled to be run on April 28. On the morning of April 28, the video team was called off the MIV test to cover a higher priority event. As an alternative to the professional video record, the experimental staff made a best effort attempt to record the test. One camera provided a plan view of the north half of the tank. A second camera was placed in-line with the jet exit on a platform just above the tank. The second camera was placed at an angle and focused on the interface at the center of the tank. The clarity of the supernatant was fair. The supernatant was green, but transparent. The organic bloom was evidently not well controlled by standard swimming pool chlorination techniques. Conditions of the test are summarized in Table 8.6.

Approximately 29 seconds after pump initiation, the first jet-interface interaction was observed and recorded by the second video camera. As evident on the video record of the angled camera, gas was released from the sludge. The gas bubbles carried up fines from the interface and quickly clouded the supernatant so that tracking of the nominal jet position was not possible. Gas bubbles tended to be released in swarms, as areas of the sludge were progressively disturbed. The test was terminated after the interface was essentially at the top surface, nearly 29 minutes after pump initiation. 


\subsubsection{Measurement Results for MIV \#2}

Time history of the two monitored temperatures is presented in Figure 8.6. The temperature difference between the sludge and supernatant temperatures was approximately $2^{\circ} \mathrm{C}$. As was the case for MIV \#1, MIV \#2 was essentially isothermal.

The process flow measurement time history is presented in Figure 8.7. The total flow was $10 \mathrm{gpm}$ (measured) which corresponded to $10 \mathrm{gpm} / \mathrm{jet}$. Flow rate delivery was constant at a nominal $10 \mathrm{gpm}$ throughout the duration of MIV $\# 2$.

Table 8.6. Conditions for MIV \#2

$\begin{array}{ll}\text { Jet Configuration } & \text { single } \\ \text { Total flow rate } & 10 \mathrm{gpm} \\ \text { Flow rate per jet } & 10 \mathrm{gpm} \\ \begin{array}{l}\text { Maximum pressure before } \\ \text { breakthrough }\end{array} & 140 \mathrm{psi} \text { (indication only) }\end{array}$

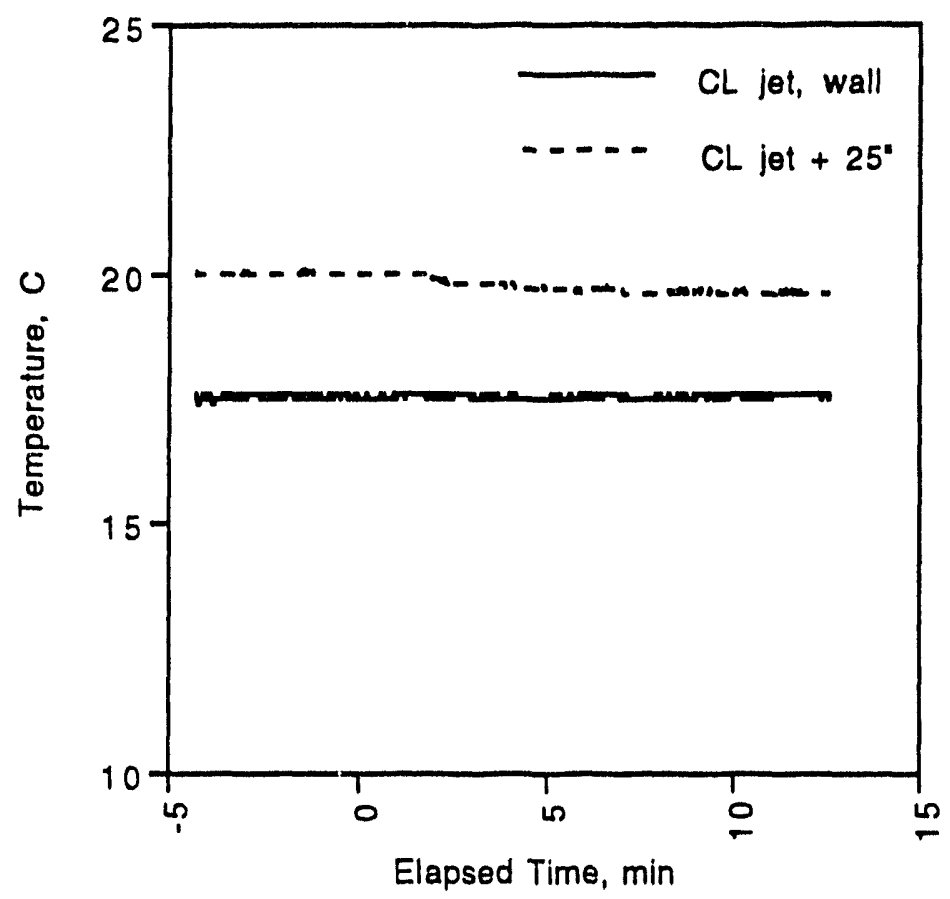

Figure 8.6. MIV \#2 Temperature 
Estimates of the location of the jet at various elapsed time after pump initiation were obtained in the same manner as for MIV \#1. Summaries of the jet location and the interface (distance from the air-supernatant surface to the supernatant-sludge surface) are presented in Tables 8.7 and 8.8.

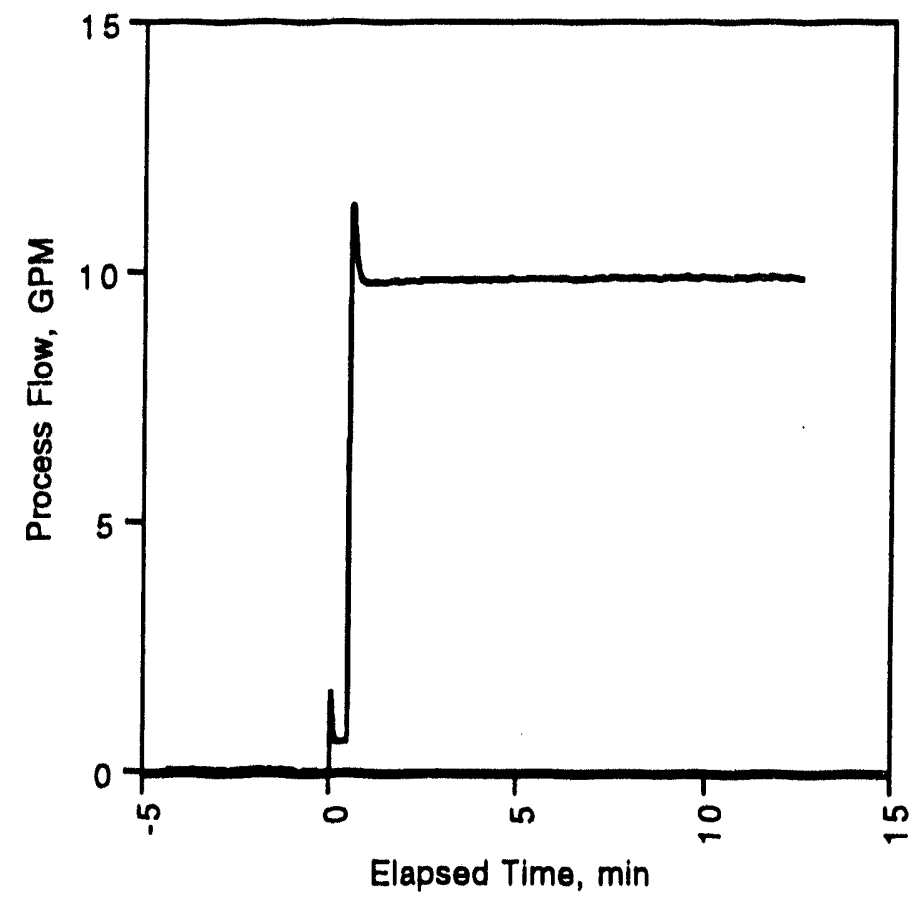

Figure 8.7. MIV \#2 Process Flow

Table 8.7. MIV \#2 Jet - Progression Table

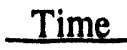

$0 \mathrm{sec}$

$29.5 \mathrm{sec}$

$34 \mathrm{sec}$

$39.6 \mathrm{sec}$

Location

na

a

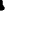

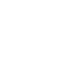


Table 8.8. Interface Location for MIV \#2

$\begin{array}{rl}\begin{array}{r}\text { Time } \\ (\mathrm{sec})\end{array} & \begin{array}{l}\text { Interface Distance } \\ \text { Below Surface (in) }\end{array} \\ 0 & 20^{n} \\ 151 & 20^{n} \\ 788 & 15^{\prime \prime} \\ 987 & 14^{n} \\ 1042 & 8^{n} \mathrm{~N} \\ 1091 & 10^{n} \mathrm{SW} \\ 1122 & 10^{n} \mathrm{SE} \\ 1164 & \text { at wall } \\ 1183 & 6-7^{n} \\ 1388 & 4.5^{\prime \prime} \\ 1420 & 4.5^{n} \text { SW } \\ 1717 & 3^{n} \mathrm{~S} \\ 1717 & \text { surface, centerline, N }\end{array}$

\subsection{Mixing Interface Visualization (MIV) Test $\# 3$}

Unlike the other tests, MIV \#3 is a single point observation of the location of the jet-interface interaction after the simulant had settled for $\mathbf{4 0}$ hours. Conditions of the test are summarized in Table 8.9.

The observed initial breakthrough was $12 \frac{1}{2}$ in. off center to the west at 30 seconds after pump initiation. The nominal process flowrate, and hence the nozzle flowrate, was $15 \mathrm{gpm}$, as shown in Figure 8.8. The delivered flowrate was stable throughout the duration of the test. The jet was discovered to be 30 degrees west of the original north discharge position. The temperature time history for MIV \#3, Figure 8.9, shows a number of unusual readings for the thermocouple at the

Table 8.9. Conditions for MIV \#3

\author{
Jet Configuration \\ Total flow rate \\ Flow rate per jet \\ Maximum Pressure before \\ breakthrough
}

$$
\begin{aligned}
& \text { single } \\
& \sim 15 \mathrm{gpm} \\
& \sim 15 \mathrm{gpm} \\
& 130 \mathrm{psi} \text { (indication } \\
& \text { only) }
\end{aligned}
$$




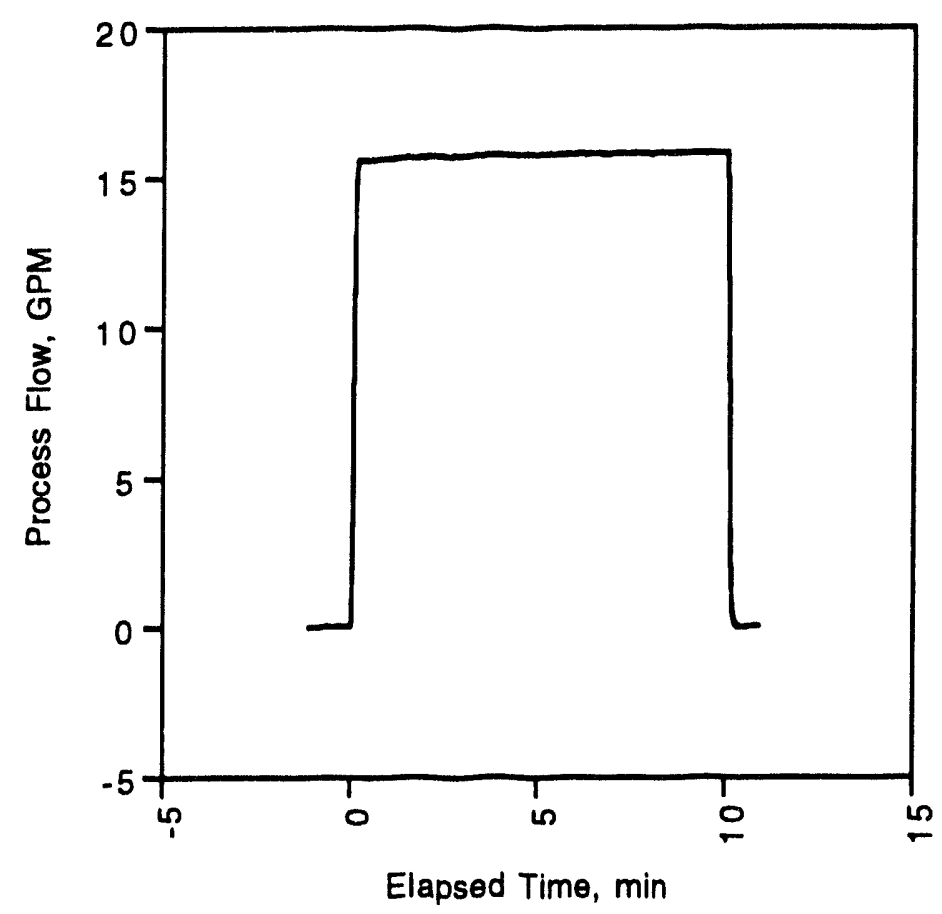

Figure 8.8. MIV \#3 Process Flow

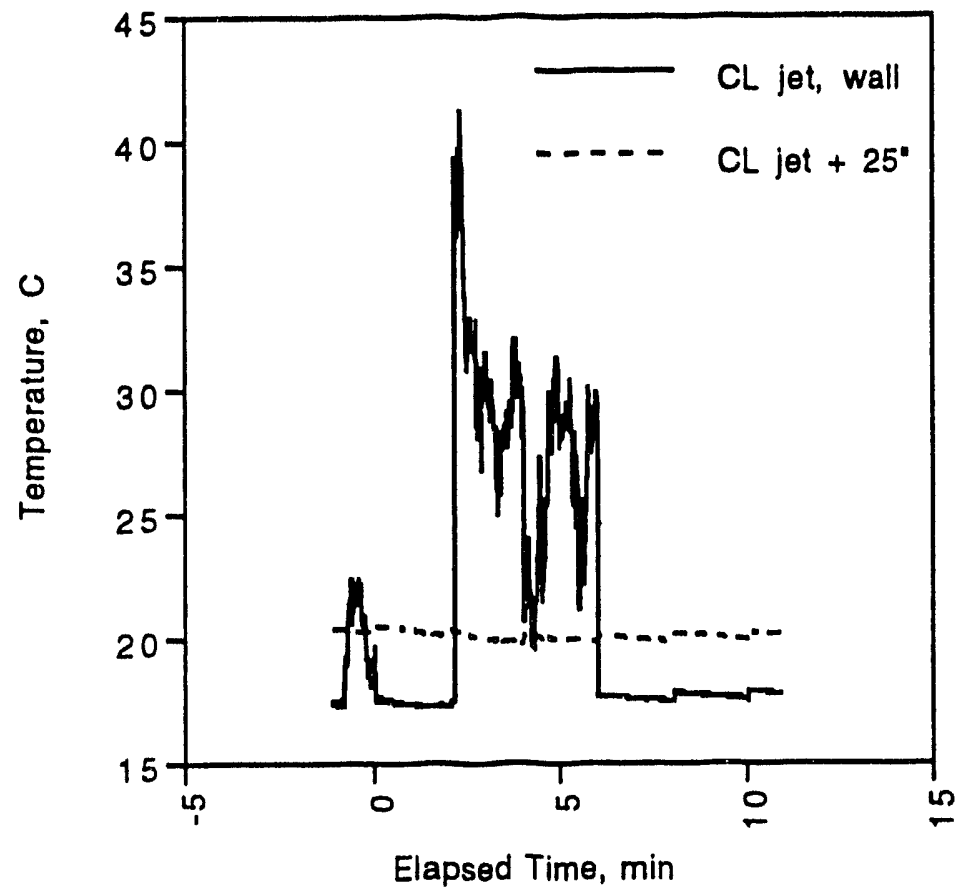

Figure 8.9. MIV \#3 Temperature 
same height as the jet exit, located on the southeast wall of the tank. Given the thermal inertia of the tank, its contents, the essentially steady ambient environment, and the lack of significant energy input, the fluctuations appear spurious.

\subsection{Mixing Interface Visualization (MIV) Test \#4}

The test initially scheduled to be run on April 28 with the video staff was rescheduled for May 5. The simulant was remixed on April 30. On May 5, a MIV test was run and recorded by the professional video staff. Three cameras were used to record the test. As before, one camera provided a plan view of the entire tank. The second camera provided a plan view of the north half of the tank. The third camera was placed in-line with the jet exit on a platform just above the tank. The third camera was placed at an angle and focused on the interface at the center of the tank. The clarity of the supernatant was good. The supernatant was light yellow-green, but transparent. Conditions of the test are summarized in Table 8.10.

Approximately 3 seconds after pump initiation, the first jet-interface interaction was observed, and was recorded by the third video camera. A few gas bubbles were released, but this did not continue. Therefore, it was assumed that the observed gas was trapped air which had not been released during the preparatory venting. During the test set-up there had been a problem with a leaking fitting. A small amount of entrained air evidently was not vented, and was expelled through the discharge leg. The test was terminated after the interface reached the top surface, nearly 31 minutes after pump initiation.

\subsubsection{Measurement Results for MIV \#4}

Time history of the two monitored temperatures is presented in Figure 8.10. The nominal temperature difference between the sludge and supernatant temperatures was approximately $2{ }^{\circ} \mathrm{C}$. The observed fluctuations in the temperature at the jet centerline at the wall appear spurious, given the thermal inertia of the tank, its contents, and the essentially steady ambient environment. The temperature fluctuations of thermocouple aro fewer and lower in magnitude than observed for MIV \#3.

Table 8.10. Conditions for MIV \#4

Jet Configuration
Total flow rate
Flow rate per jet
Maximum pressure before
breakthrough

single

$\sim 10 \mathrm{gpm}$

$\sim 10 \mathrm{gpm}$

$32 \mathrm{psi}$ (indication only) 


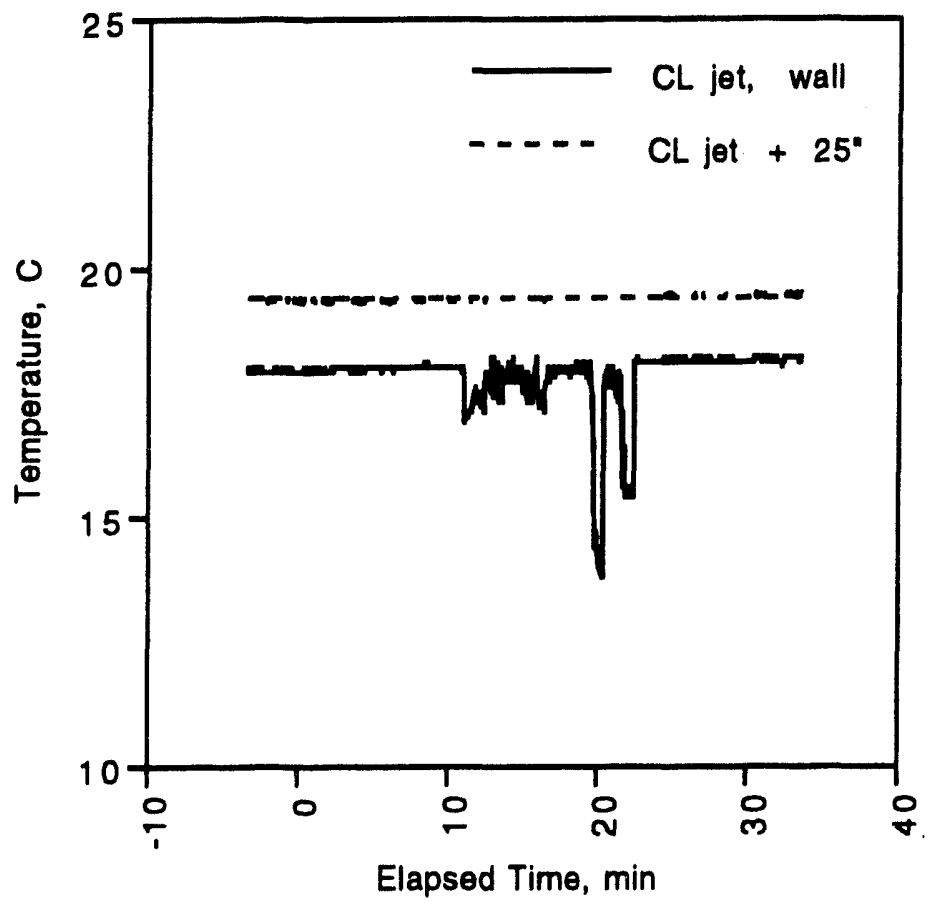

Figure 8.10. MIV \#4 Temperature

The process flow measurement time history is presented in Figure 8.11. The total flow was nominally $10 \mathrm{gpm}$ (measured), which corresponded to $10 \mathrm{gpm} / \mathrm{jet}$. Flowrate delivery was, on average, nominally $10 \mathrm{gpm}$. The reason for the fluctuations of the flowrate throughout the duration of MIV \#4 is under investigation.

Estimates of the location of the jet at various elapsed times after pump initiation were obtained as previously described. Summaries of the jet location and the interface (distance from the airsupernatant surface to the supernatant-sludge surface) are presented in Tables 8.11 and 8.12.

\subsection{Shear Strength Measurements for Mixing Interface Visualization Tests}

Results of the shear strength measurements taken in support of the MIV tests are reported in this section. Because of the test schedule and repairs required for the shear-vane equipment, no preliminary testing of the system was performed. Due to difficulties associated with obtaining the data and the small number of tests performed, these results should be viewed as indications of magnitude rather than specific values. An uncertainty analysis was not performed for these results. 


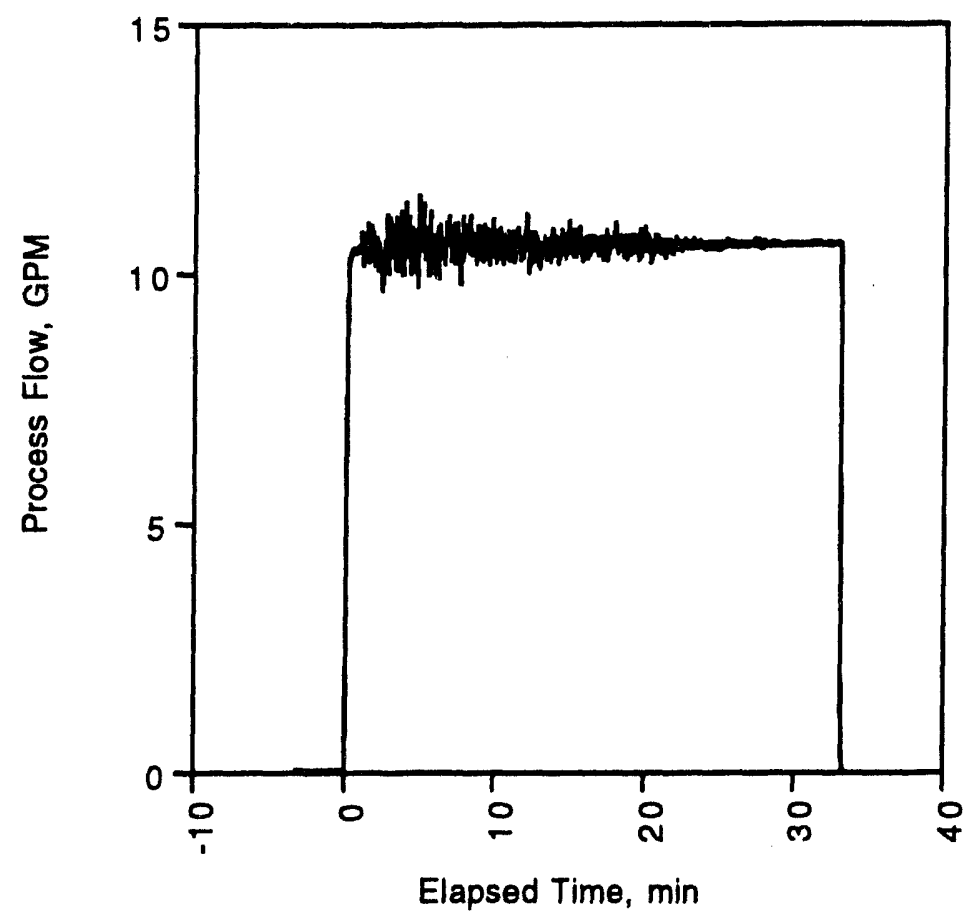

Figure 8.11. MIV \#4 Process Flow

Table 8.11. MIV \#4 Jet - Progression Table

\begin{tabular}{|c|c|}
\hline Time & Location \\
\hline $0 \mathrm{~s}$ & na \\
\hline $3.42 \mathrm{~s}$ & at pump barrel \\
\hline $31 \mathrm{~s}$ & $12-12^{3 / 4} " \mathrm{~N}$ \\
\hline (55s) & $1-2^{\prime \prime} \mathrm{W}$ \\
\hline $112 \mathrm{~s}$ & $20-205 / 8 " \mathrm{~N}$ \\
\hline (138s) & $\sim 2^{\prime \prime} W$ \\
\hline $196 \mathrm{~s}$ & $24-24^{27 / 32 " ~ N ~}$ \\
\hline (222 s) & $0-1 " W$ \\
\hline $313 \mathrm{~s}$ & $28-28^{27 / 32} \mathrm{~N}$ \\
\hline (317 s) & $0^{\prime \prime} \mathrm{W}$ \\
\hline
\end{tabular}

Note: The time listed in parentheses is time of subsequent observation of interface/jet interaction at the same nominal location. 
Table 8.12. Interface Location for MIV \#4

$\begin{array}{rl}\begin{array}{r}\text { Time } \\ (\mathrm{sec})\end{array} & \begin{array}{l}\text { Interface Distance } \\ \text { Below Surface (in) }\end{array} \\ 0 & 20 \\ 119 & 16 \\ 167 & 16 \\ 331 & 12 \\ 431 & \text { jet at N wall } \\ 448 & 12 \\ 587 & 10 \\ 723 & 71 / 2-8 \\ 751 & 8 \\ 761 & 8 \\ 842 & 71 / 2 \\ 863 & 61 / 2 \\ 881 & 61 / 2 \\ 978 & 51 / 2 \\ 999 & 5 \\ 1090 & 4-31 / 2 \\ 1118 & 4 \\ 1193 & 31 / 2 \\ 1872 & 3 / 4\end{array}$

The simulant has shown thixotropic behavior when tested in the laboratory and its shear strength has been observed to be time dependent over the course of a month during previous testing (FY 1992 1/12-scale tests and FY 1993 bench-scale tests).

\subsubsection{Shear Strength Equipment}

The shear strength measurements were made using a shear vane tester designed and fabricated by PNL for use with the $1 / 12$-scale facility. The shear strength was obtained by measuring the maximum torque that results from rotating a vane inserted in the sludge. As described in section 3.2, the vane consists of four perpendicular, rectangular fins attached to the bottom of a shaft.

The vane fabricated for these tests was $2.5 \mathrm{in}$. high and $2.5 \mathrm{in}$. across. The dimensions of the vane were based on previous shear strength measurements made in the laboratory. Laboratory measurements of shear strength had ranged from $890-4700 \mathrm{dyne} / \mathrm{cm}^{2}$, on samples extracted from the 1/12-scale tank during previous tests (Fort et al. 1993). In-situ measurements were expected to be somewhat higher. The vane was sized so that 4700 dyne $/ \mathrm{cm}^{2}$ was $70 \%$ of full scale and resulted in a maximum allowable shear strength measurable by the system of $9800 \mathrm{dyne} / \mathrm{cm}^{2}$. 
The torque was measured using a strain gage reaction torque sensor with a $50 \mathrm{oz}$.-in. capacity and $50 \%$ overload. A strain gage conditioner provided excitation to the torque sensor, gave a digital reading of torque and supplied a voltage to the data acquisition system (DAS). The vane was rotated using a $1 / 8 \mathrm{hp}$, electric motor with 120:1 gear reduction. The motor speed was controlled from the mixing pump control board. The motor drove a 124.8:1 in-line, same rotation, gear reducer.

A post-test calibration of the strain gage conditioner was performed. The calibration yielded an accuracy of $\pm 0.5 \mathrm{oz}$.-in. for the strain gage conditioner. The majority of this uncertainty was due to the calibration setup.

\subsubsection{Shear Vane Procedure}

The shear vane tests were performed in the shear-vane tank to avoid disturbing the $1 / 12$-scale tank for simulant sampling. Before each MIV test, the simulant from the shear-vane tank was transferred to the 1/12-scale tank and the entire simulant inventory remixed. The shear-vane tank was then filled with simulant to the same height as in the 1/12-scale tank. This process was performed to ensure that the shear-vane tank sludge layer was representative of that in the $1 / 12$-scale tank at the time of testing.

For MIV \#1-3, the shear vane was placed in the shear-vane tank at the time the tank was filled. For MIV \#4, the vane was inserted into the sludge just before testing. For all tests, the bottom of the vane was placed 3.5 in. from the tank floor, corresponding to the height of the top of the jet nozzle. Before each test, a bridge shunt calibration was performed by temporarily unbalancing the bridge by a known amount to yield a known calibration value.

At the beginning of each test, a zero reading was obtained and then the test run was initiated by turning on the motor. The test run was terminated by turning off the motor. At the completion of the test run, the vane was raised out of the sludge without rotating the vane, and the motor was again started. The torque was recorded as the continuous rotation dry-run torque. The vane was then rewound to its original orientation and the rewound dry-run torque was measured. The average of the continuous rotation and rewound dry-run torques was used as the torque resulting from motor and bearing friction.

Data was recorded manually from the strain gage conditioner readout as well as by a voltage signal monitored by the DAS. DAS problems resulted in use of the manually recorded data to complete the analysis.

The maximum back pressure that built up before the flow broke through the sludge during the MIV tests was recorded manually, and used for the shear strength analysis. The gage used to obtain the back pressure was for indication only. The height of the sludge and supernatant liquid were measured in order to calculate the sludge packing fraction. The sludge level was easier to measure in the shear-vane tank because of the transparent walls. 


\subsubsection{Shear Vane Test Data}

The following subsections present a brief description of each shear vane test and the pertinent data obtained. Table 8.13 provides a summary of the results obtained. Reiterating, the results should be viewed only as indications of magnitude.

\subsubsection{MIV \#1 Shear Vane Test}

The sludge was $116 \mathrm{hrs}$ old and had been settling for $116 \mathrm{hrs}$. The maximum torque observed was $54 \mathrm{oz}$.-in. The frictional torque was $3.1 \mathrm{oz}$.-in. When the vane was raised at the completion of the test run, a large ball of sludge was attached to the vane. The sludge ball was 4.5 in. at its widest and 8.5 in. at its longest. The ball was approximately 4 in. across throughout 5 in. of its midsection. The bottom 2 in. was tapered to a point. It was assumed the sludge ball could be approximated as a cylinder of sludge with a height of 6 in. and a diameter of $4 \mathrm{in}$. The peak back pressure observed was 42 psi before the jet breakthrough in the 1/12-scale tank. The volume percent of solids in the $1 / 12$-scale tank's packed sludge was $42.3 \%$. Measurements were not available for the shearvane tank.

\subsubsection{MIV \#2 Shear Vane Test}

The sludge was $452 \mathrm{hrs}$ ( 18.8 days) old and had been settling for $114 \mathrm{hrs}$ ( 4.75 days). The sludge never yielded and the test had to be terminated when the torque reached $81 \mathrm{oz}$.-in. to avoid damaging the equipment. The frictional torque was measured at $5.2 \mathrm{oz}$.-in. A sludge ball 3 in. high and 4 in. across was attached to the fins when the vane was pulled from the tank. The attached sludge was assumed to approximate a cylinder 3 in. high with a 4 in. diameter. The peak back pressure observed at the beginning of MIV \#2 was $140 \mathrm{psi}$. The volume percent of solids in the sludges of the $1 / 12$-scale and shear-vane tanks was $42.2 \%$ and $44.9 \%$, respectively.

Table 8.13. Viscosity Estimates for Sludge Layer

\begin{tabular}{|c|c|c|c|c|c|c|}
\hline \multirow[t]{2}{*}{$\begin{array}{l}\text { MIV Test } \\
\text { No. } \\
\end{array}$} & \multirow[t]{2}{*}{$\begin{array}{c}\text { Sludge Age } \\
\text { (hrs) }\end{array}$} & \multirow[t]{2}{*}{$\begin{array}{c}\begin{array}{c}\text { Settling Time } \\
\text { of Sludge } \\
\text { (hrs) }\end{array} \\
\end{array}$} & \multicolumn{2}{|c|}{$\begin{array}{c}\text { Volume } \% \text { of Solids in } \\
\text { Packed Sludge } \\
(\%)\end{array}$} & \multirow[t]{2}{*}{$\begin{array}{c}\text { Shear Strength } \\
\left(\text { dyne } / \mathrm{cm}^{2}\right) \\
\end{array}$} & \multirow[t]{2}{*}{$\begin{array}{c}\text { Viscosity } \\
\text { (cP) }\end{array}$} \\
\hline & & & $1 / 12 \mathrm{Sc} \operatorname{Tnk}^{(\mathrm{a})}$ & Vane Tnk ${ }^{(b)}$ & & \\
\hline 1 & 116 & 116 & 42.3 & --- & 1200 & 5100 \\
\hline 2 & 452 & 114 & 42.2 & 44.9 & $4200^{(c)}-5700^{(c)}$ & -- \\
\hline 3 & 494 & 40 & 39.7 & --- & $3900^{(c)}-5300^{(c)}$ &.- \\
\hline 4 & 523 & 115 & 43.2 & 44.2 & 1300 & 4200 \\
\hline
\end{tabular}

(a) 1/12-scale DST Tank (Volume $\%$ of solids in packed sludge of the $1 / 12$ sale tank.

(b) Shear Vane Test Tank (Volume $\%$ of solids in packed sludge of the shear vane)

(c) Values of shear strength not calculated directly from shear vane test data. 


\subsubsection{MIV \#3 Shear Vane Test}

The sludge was $494 \mathrm{hrs}$ (20.5 days) old and had been settling for $40 \mathrm{hrs}$ (1.67 days). During the test run, a torque of $55 \mathrm{oz}$.-in. was obtained and maintained for a few moments and then a torque of $86 \mathrm{oz}$.-in. was achieved at which time the test was terminated. The frictional torque was measured at $4.75 \mathrm{oz}$.-in. Excess simulant was observed attached to the fins when the vane was raised, but the material sloughed off too quickly for any measurements on the attached simulant: however, the sludge remained attached between the fins. The peak back pressure observed for MIV \#3 was $130 \mathrm{psi}$. The 1/12-scale tank's packed sludge had a solids volume percent of $39.7 \%$.

At the completion of the first shear strength test for MIV \#3, the vane was reinserted into the sludge in a new position and another test run was conducted. The sludge never yielded, and the test was terminated when the torque reached $85 \mathrm{oz}$.-in. The vane relaxed back to $20 \mathrm{oz}$.-in. in $6 \mathrm{~min}$., and indicated a torque of $12.4 \mathrm{oz}$.-in. after $55 \mathrm{~min}$. The torque remained at $12.4 \mathrm{oz}$.-in. for an additional $30 \mathrm{~min}$. The vane was left undisturbed in the same location, and $3 \mathrm{hrs}$ after the previous test the motor was again started. The torque again rose to $85 \mathrm{oz}$.-in., at which the time the test was terminated. The torque relaxed back to $23.5 \mathrm{oz}$.-in. after $7 \mathrm{~min}$.

\subsubsection{MIV \#4 Shear Vane Test}

The sludge was $523 \mathrm{hrs}$ ( 21.8 days) old and had been settling for $115 \mathrm{hrs}$ ( 4.8 days). The vane was inserted into the sludge just before the test run. The sludge yielded at $18.2 \mathrm{oz}$.-in. and the frictional torque was measured at $5.75 \mathrm{oz}$.-in. When the vane was pulled from the tank, sludge was clinging within the fins, but no excess material was attached to the outer edges of the vane. The peak back pressure observed for MIV \#4 was $32 \mathrm{psi}$. The volume percent of solids in the sludges of the $1 / 12$-scale and shear-vane tanks was $43.2 \%$ and $44.2 \%$, respectively.

\subsubsection{Shear Strength Results}

Shear strength values were calculated using three different sets of assumptions. The first set of calculations assumes that the shearing area is the total surface area of cylinder created by the outer edges of the vane's fins. The assumed cylinder is $2.5 \mathrm{in}$. high and has a diameter of $2.5 \mathrm{in}$. The second set of assumptions uses a shear area equal to the area of the cylinders approximated from the excess material attached to the vane. The preceding section gives the estimated dimensions of these cylinders.

Because the sludge never yielded in MIV $\# 2$ and $\# 3$, an attempt was made to estimate the shear strength by yet another method. This method asserts that the sludge's shear strength is proportional to the maximum back pressure required to break through the sludge packed in the nozzles. The ratios of shear strength to back pressure for MIV \#1 and $\# 4$ were used to estimate a range of shear strength. Table 8.14 shows the results of the three sets of calculations.

The shaft torque associated with the resistance created by the sludge contacting the vane shaft was estimated to be 10 to 50 dyne-cm, based on previous viscosity measurements. Shaft torques of these magnitude result in differences of $.5-2.5$ dyne $/ \mathrm{cm}^{2}$ in the shear strength measurements. 
It is possible to obtain yield strength data with the shear vane, but this procedure was not included in the testing reported here.

It is also possible to calculate sludge viscosity from shear vane data. Because the sludge did not yield in MIV \#2 and \#3 shear vane tests, the data necessary to calculate viscosity was not obtained. The method used to calculate viscosity was based on (Heath 1987). The method uses a correlation relating the Reynolds Number $(\mathrm{Re})$ to the Power Number $(\mathrm{Np})$. Np is a dimensionless value of the ratio of the pressure differences producing flow to the inertial forces, $N p=f\left(T_{v}, w, p, D, S\right)$ where:

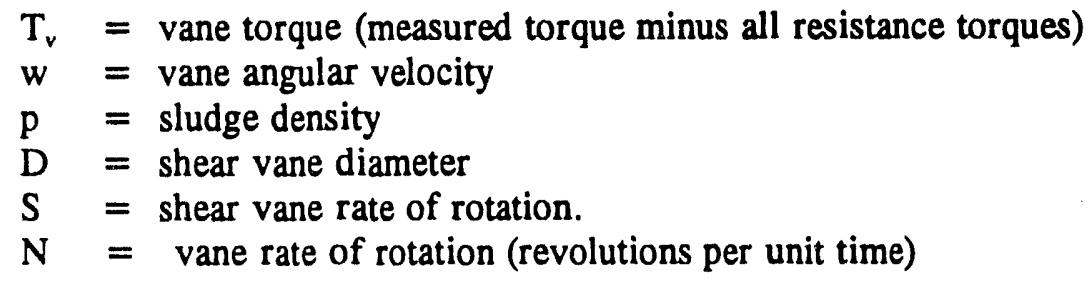

The correlation between $\mathrm{Re}$ and $\mathrm{Np}$ is considered valid for $\mathrm{Re}<15$. $\mathrm{Re}$ is determined from the $\mathrm{Np}$, and the viscosity, $\mathrm{n}$, is calculated from the Re:

$$
\begin{aligned}
& \log \mathrm{Np}=-(0.977) \log \mathrm{Re}+2.190 \quad \text { (Equation } 5.10 \text { in Heath, 1987) } \\
& \text { and } \mathrm{n}=\mathrm{pD}^{2} \mathrm{~N} / \mathrm{Re} .
\end{aligned}
$$

The viscosity of MIV \#1 was calculated based on the vane dimensions and again based on the approximated cylinder dimensions. The viscosity was also calculated for MIV \#4. The strain rate at which the viscosity measurements were made was estimated to be $0.009 \mathrm{~s}^{-1}$. This estimate was calculated using relationships developed in (Heath 1987). Table 8.15 shows the results of the viscosity calculations.

\begin{tabular}{|c|c|c|c|c|c|}
\hline \multirow[b]{2}{*}{$\begin{array}{l}\text { MIV } \\
\text { Test } \\
\text { No. } \\
\end{array}$} & \multicolumn{2}{|c|}{ Measured Shear Strength } & \multirow[b]{2}{*}{$\begin{array}{c}\text { Maximum Back } \\
\text { Pressure MIV } \\
\text { Tests (psi) } \\
\end{array}$} & \multirow[b]{2}{*}{$\begin{array}{l}\text { Ratio of Shear } \\
\text { Strength to } \\
\text { Back Pressure } \\
\left.\text { (dyne } / \mathrm{cm}^{2} / \mathrm{psi}\right)\end{array}$} & \multirow[b]{2}{*}{$\begin{array}{c}\text { Estimated Shear } \\
\text { Strength } \\
\left(\text { dyne } / \mathrm{cm}^{2}\right) \\
\end{array}$} \\
\hline & $\begin{array}{c}\text { Based on } \\
\text { Vane Shear } \\
\text { Area } \\
\left(\text { dyne } / \mathrm{cm}^{2}\right) \\
\end{array}$ & $\begin{array}{c}\text { Based on } \\
\text { Attached Sludge } \\
\text { Shear Area } \\
\left.\text { (dyne } / \mathrm{cm}^{2}\right) \\
\end{array}$ & & & \\
\hline 1 & 6700 & 1200 & 40 & $29.75^{\bullet}$ & 1200 \\
\hline 2 & +10000 & +3000 & 140 & - & $4200-5700$ \\
\hline 3 & 6600 & - & 130 & - & $3900-5300$ \\
\hline 3 & +10700 & - & & & \\
\hline 4 & 1300 & 1300 & 32 & $40.5^{(\bullet)}$ & 1300 \\
\hline
\end{tabular}

Table 8.14. Shear Strength Values for Sludge Layer

(a) The ratio was calculated using the shear strength determined assuming the shear area of the attached sludge. 


\subsection{Shear Vane Conclusions}

Considering the lack of sufficient test data and the varying results, the values for shear strength and viscosity should not be taken as exact measurements. Instead, the results should be regarded as magnitude estimates. The most reliable results are those from the MIV \#4 test. The MIV \#4 data did not rely on an estimate of shear area, and a peak torque was clearly observed.

Previous tests, (Fort et al. 1993) and bench scale tests, had shown qualitatively that the shear strength of the simulant is time dependent. The simulant has exhibited a weak shear strength for approximately the first week after being mixed. Between the first and second week, the shear strength seemed to increase a great deal. The simulant maintained this higher shear strength for 2 to 3 weeks. During this period, it appeared that the shear strength was independent of how many times the simulant was remixed. After this period of high shear strength the simulant's shear strength began to decline back to its original value. This is the same trend that was observed in the shear vane tests and the peak back pressure trend observed during MIV testing.

Despite the limited results of these tests, the shear vane has the potential to aid in characterizing test simulants in situ during scaled experiments. With some slight modifications to the equipment and the test procedure, the shear vane can provide shear strength, yield strength, and viscosity measurements as a function of shear rate, by testing at various motor speeds for in-situ sludges.

Table 8.15. Viscosity Estimates for Sludge Layer

$\begin{array}{ll}\text { MIV Test No. } & \begin{array}{l}\text { Assumed Vane } \\ \text { Diameter (in.) }\end{array}\end{array}$

Viscosity (cP)

4200 


\subsection{Conclusions}

Video records of jet-sludge breakthrough were completed in the $1 / 12$-scale facility. The quick onset and sustained growth of organics in the simulant reduced the quality of the visual observations. The limitations of the video derived observations include:

- A time lag between occurrence of breakthrough and seeing the breakthrough at the surface.

- Difficulty in determining jet progression because of surface waves and particulate fines becoming suspended in the supernatant.

- A range reported for some positions. For MIV \#1 and MIV \#4 the position was bounded by referencing to both the north platform grate and the nominal pump centerline. The position values corresponded fairly well, typically within 2 in. of each other.

- The reported video-derived position is only a nominal center of the region of disruption.

Improvements in the visualization technique can be made, such as orientation of the grid, definitive marking of key grid lines, and image recording techniques. Before completion of additional $1 / 12$-scale tests, it is recommended that a strategy of chemical treatment be developed to inhibit organic bloom. This treatment should be implemented as soon as the simulant has been prepared, before organic growth is noticed.

Revisions to the loop and in-tank instrumentation should be considered to improve the quantitative information derived from the tests. For example, pressure instrumentation in the process line would provide a pressure history that would define flow' initiation as well as indicate relative simulant shear strength.

Simulant shear strength has been observed to be time dependent. The shear strength tends to increase over the first 2 to 3 weeks of aging, then to decrease. The time dependent trend was observed from both the shear vane tests and the peak back pressures noted during MIV testing.

Simple time histories of nominal jet location and interface height are shown in Figure 9.1 and 9.2 , respectively. Based on shear vane observations, simulant cohesion tended to decrease over time. Hence, the jet in MIV \#4 apparently traveled at a faster rate than the jet of MIV \#1, Figure 9.1. The rate of interface rise for MIV \#4 tended to be larger than for MIV \#2, Figure 9.2; which is consistent with the decrease in shear strength beyond the simulant age of 2 to 3 weeks. The interface histories for MIV \#1 and MIV \#4 are similar in shape though slightly offset. The offset is expected since the total flow rate of MIV \#1 is approximately twice that of MIV \#4.

Results of the limited testing performed to date have indicated that the shear vane has the potential to aid in characterizing test simulants in-situ for scaled experiments. Slight modifications to the equipment and the shear vane test procedure could provide shear strength, yield strength, and viscosity measurements as a function of shear rate, by testing at various motor speeds for in-situ sludges. 


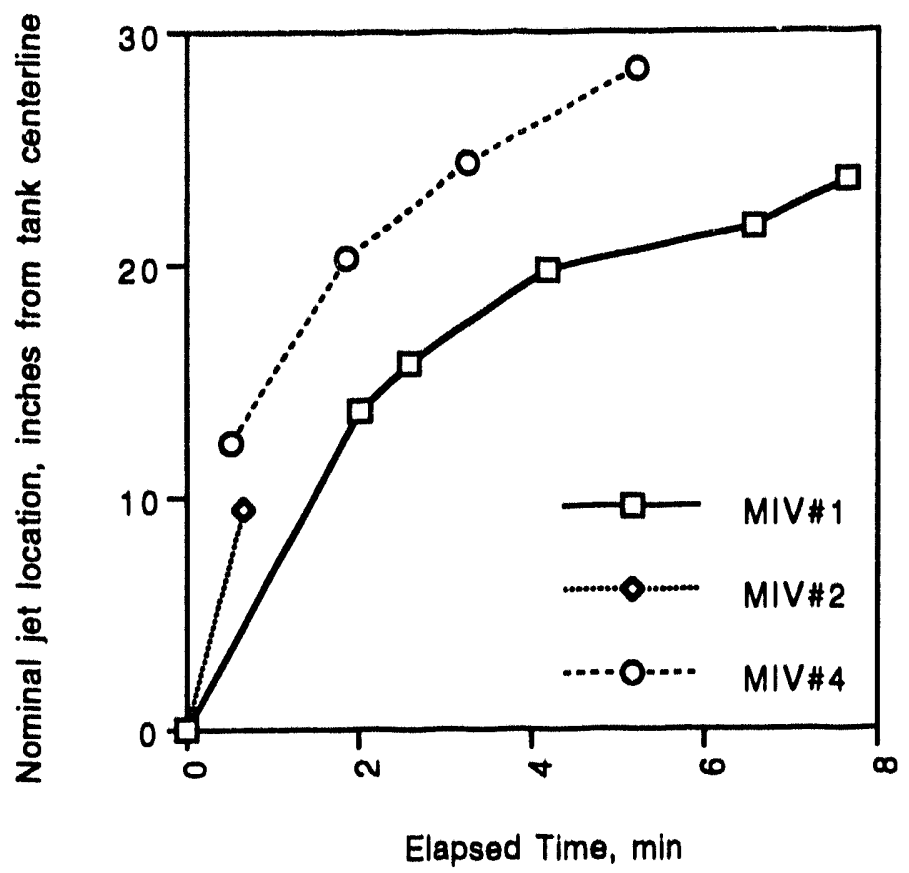

Figure 9.1. Jet Location Comparison

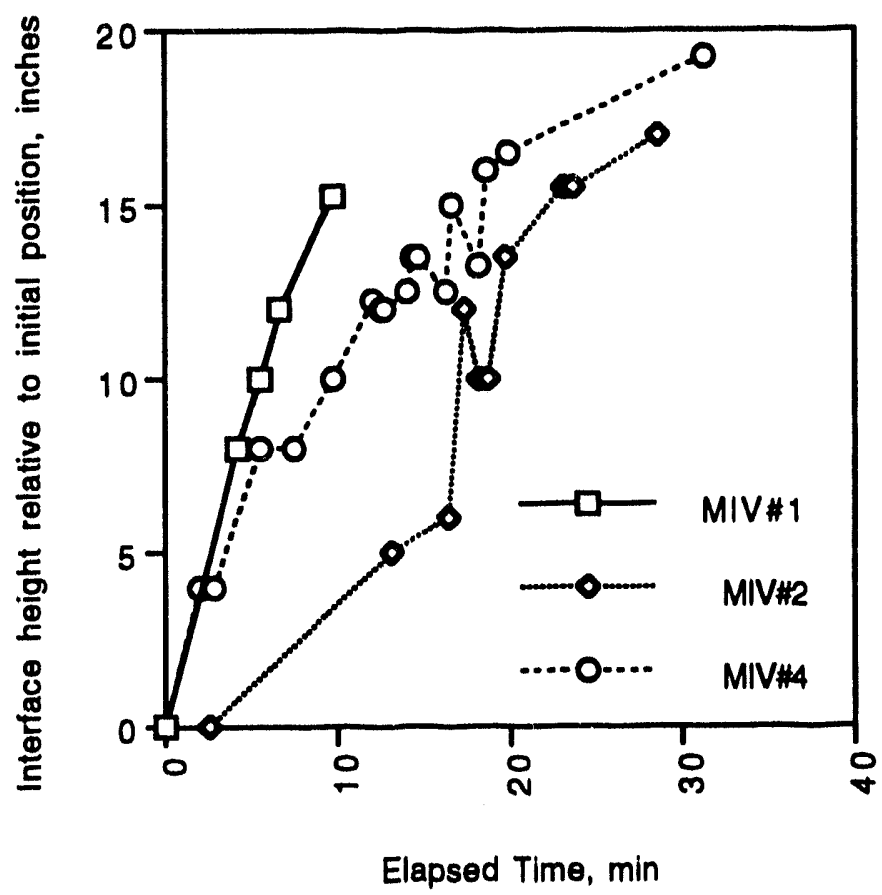

Figure 9.2. Interface Position 


\subsection{References}

Abraham, G. 1963. Jet Diffussion (sic) in Stagnant Ambient Fluid. Delft Hydraulics Laboratory, Publication No. 29. Waterloopkundig Laboratorium, Delft, The Netherlands.

Fort, J. A., J. A. Bamberger, J. M. Bates, C. W. Enderlin, and M. R. Elmore. 1993. 1/12 Scale Physical Modeling Experiments in Support of Tank 241-SY-101 Hydrogen Mitigation. PNL-8476, Pacific Northwest Laboratory, Richland, Washington.

Heath, W. O. 1987. Development of an In Situ Method to Define the Rheological Properties of Slurries and Sludges Stored in Underground Tanks. PNL-6083, Pacific Northwest Laboratory, Richland, Washington.

Liljegren, L. M. 1993. Similarity Analysis Applied to the Design of Scaled Tests of Hydraulic Mitigation Methods for 241-SY-101. PNL-8518, Pacific Northwest Laboratory, Richland Washington.

Trent, D. S., and L. L. Eyler. 1991. TEMPEST, A Computer Program for Three Dimensional TimeDependent Hydrothermal Analysis. PNL-4348, Pacific Northwest Laboratory, Richland Washington. 


\section{Distribution}

No. of

Copies

12 DOE Office of Scientific and Technical Information

C. S. Abrams

1987 Virginia

Idaho Falls, ID 83404

N. E. Bibler

Westinghouse Savannah

River Co.

Bldg. 773A, Room B132

Box 616

Aiken, SC 29802

D. Campbell

102 Windham Road

Oak Ridge, TN 37830

F. N. Carlson

6905 North, 5th West

Idaho Falls, ID 83401

G. R. Choppin

Department of Chemistry B-164

The Florida State University

Tallahassee, FL 32306

M. First

Harvard School of Public

Health

665 Huntington Avenue

Boston, MA 02115

C. W. Forsberg

Oak Ridge National Laboratory

MS-6495, P.O. Box 2008

Oak Ridge, TN 37831-6495
No. of

Copies

C. Grelecki

Hazards Research Corporation

200 Valley Road, Suite 301

Mt. Arlington, NJ 07856

E. P. Horwitz Chemistry Division

Argonne National Laboratory

9700 Cass Avenue

Argonne, IL 60439-4831

B. C. Hudson

Lawrence Livermore National Laboratory

Nuclear Test Containment

Program

P.O. Box 808, L-221

East Avenue

Livermore, CA 94550

B. R. Kowalski

Chemistry Department BG-10

University of Washington

Seattle, WA 98195

6 Los Alamos National Laboratory

P.O. Box 1663

Los Alamos, NM 87545

Attn: L. H. Sullivan, K557

J. R. White, K555

S. W. Eisenhawer, K557

J. Edwards, K557

J. Hanson, H509

T. E. Larson, P915

J. L. Mai

723 45th Avenue

San Francisco, CA 94121

Distr.1 
No. of

Copies

F. L. Parker

Vanderbilt University

P.O. Box 1596, Station B

Nashville, TN 37235

G. Powers

Design Science, Inc.

163 Witherow Road

Sewickley, PA 15143

G. A. Russell

Professor of Chemistry

Iowa State University

Gilman Hall

Ames, IA 50011-3111

\section{A. Schneider \\ Massachusetts Institute of \\ Technology \\ Department of Nuclear \\ Engineering \\ Room 24-1098 \\ 77 Massachusetts Avenue \\ Cambridge, MA 02139}

W. W. Schulz

727 Sweetleaf Drive

Wilmington, DE 19808

D. D. Siemer

WINCO

IRC MS 2207

Idaho Falls, ID 83403

S. E. Slezak

Sandia National Laboratories

1515 Eubank N.E.

Division 6424

P.O. Box 5800

Albuquerque, NM 87185
No. of

Copies

W. J. Thomson

Dept. of Chemical Engineering

Washington State University

Pullman, WA 99164

J. Tseng, EM-35

U.S. Department of Energy

Trevion II Building

Washington, D.C. 20585-0002

G. Wallis

Associate Dean

Thayer School of Engineering

Dartmouth College

Hanover, NH 03755

\section{ONSITE}

4 DOE Richland Operations Office

R. F. Christensen, R3-72

R. E. Gerton, R3-72

J. M. Gray, R3-72

G. W. Rosenwald, R3-72

28 Westinghouse Hanford Company

H. Babad, R2-78

T. R. Beaver, H0-33

T. R. Benegas, H5-09

H. R. Brager, L5-65

T. M. Burke, S4-58

C. DeFigh-Price, R2-31

J. C. Fulton, R2-31

K. A. Gasper, R2-08

M. N. Hall, N1-42

C. E. Hanson, H5-09

G. D. Johnson, R2-78

N. W. Kirch, R2-11

W. L. Knecht, H0-34 
No. of

Copies

Westinghouse Hanford Company (Contd)

J. W. Lentsch, R2-78

R. M. Marusich, H4-60

D. M. Ogden, HO-32

M. A. Payne, R2-50

R. W. Reed, R1-51

D. A. Reynolds, R2-11

D. C. Richardson, R2-50

K. Sathyanarayana, H0-34

M. H. Shannon, H4-61

C. P. Shaw, L5-07

D. D. Stepnewski, H4-62

T. I. Stokes, H5-09

J. D. Thomson, R1-30

R. E. Vandercook, S6-17

D. D. Wodrich, R2-85
No. of

Copies

34 Pacific Northwest Laboratory

R. T. Allemann, K7-15

J. M. Alzheimer,K5-22

J. A. Bamberger, K7-15

J. M. Bates, K7-15

J. B. Colson, K5-10

C. W. Enderlin, K7-15 (4)

E. J. Eschbach, K7-15 (5)

L. L. Eyler, K7-15

B. M. Johnson, Jr., K1-78 (5)

N. J. Lombardo, K7-02

T. E. Michener, K7-15

F. M. Ryan, K7-70

R. D. Scheele, P7-25

C. L. Shephard, K5-26

D. M. Strachan, K2-44

D. S. Trent, K7-15

H. H. Van Tuyl, P7-22

Publishing Coordination, K1-06

Technical Report Files (5) 

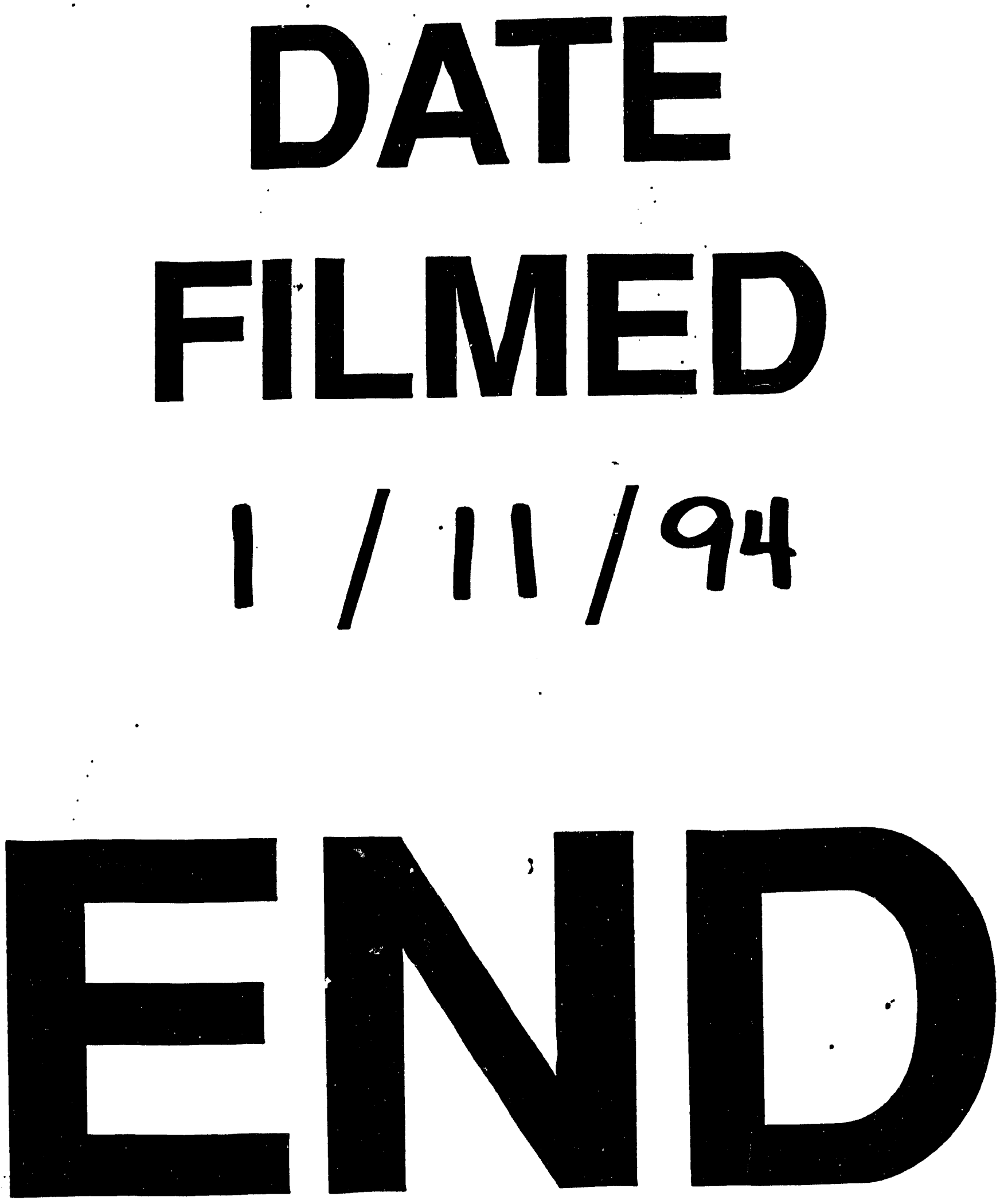
